\title{
Overexpression of 4EBP1, p70S6K, Akt1 or Akt2 differentially promotes Coxsackievirus B3-induced apoptosis in HeLa cells
}

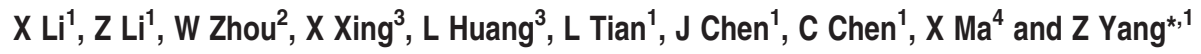

Our previous studies have shown that the inhibition of phosphatidylinositol 3-kinase (PI3K) or mTOR complex 1 can obviously promote the Coxsackievirus B3 (CVB3)-induced apoptosis of HeLa cells by regulating the expression of proapoptotic factors. To further illustrate it, Homo sapiens elF4E-binding protein 1 (4EBP1), p70S6 kinase (p70S6K), Akt1 and Akt2 were transfected to HeLa cells, respectively. And then, we established the stable transfected cell lines. Next, after CVB3 infection, apoptosis in different groups was determined by flow cytometry; the expressions of Bim, Bax, caspase- 9 and caspase-3 were examined by real-time fluorescence quantitative PCR and western blot analysis; the expression of CVB3 mRNA and viral capsid protein VP1 were also analyzed by real-time fluorescence quantitative PCR, western blot analysis and immunofluorescence, respectively. At the meantime, CVB3 replication was observed by transmission electron microscope. We found that CVB3-induced cytopathic effect and apoptosis in transfected groups were more obvious than that in controls. Unexpectedly, apoptosis rate in Akt1 group was higher than others at the early stage after viral infection and decreased with the viral-infected time increasing, which was opposite to other groups. Compared with controls, the expression of CVB3 mRNA was increased at 3, 6, 12 and $24 \mathrm{~h}$ postinfection (p. i.) in all groups. At the meantime, VP1 expression in 4EBP1 group was higher than control during the process of infection, while the expressions in the other groups were change dynamically. Moreover, overexpression of 4EBP1 did not affect the mRNA expressions of Bim, Bax, caspase-9 and caspase-3; while protein expressions of Bim and Bax were decreased, the selfcleavages of caspase-9 and caspase-3 were stimulated. Meanwhile, overexpression of p70S6K blocked the CVB3-induced Bim, Bax and caspase-9 expressions but promoted the self-cleavage of caspase-9. In the Akt1 group, it is noteworthy that the expressions of Bim protein were higher than controls at 3 and $6 \mathrm{~h} \mathrm{p}$. i. but lower at $24 \mathrm{~h} \mathrm{p}$. i., and the expression of Bax protein were higher at 6 and $24 \mathrm{~h} \mathrm{p}$. i., while their mRNA expressions were all decreased. Furthermore, overexpression of Akt1 stimulated the procaspase-9 and procaspase-3 expression but blocked their self-cleavages. Overexpression of Akt2, however, had little effect on Bim, Bax and caspase-3, while prevented caspase-9 from self-cleavage at the late stage of CVB3 infection. As stated above, our results demonstrated that overexpression of 4EBP1, p70S6K, Akt1 or Akt2 could promote the CVB3-induced apoptosis in diverse degree via different mediating ways in viral replication and proapoptotic factors in BcL-2 and caspase families. As 4EBP1, p70S6K and Akt are the important substrates of PI3K and mammalian target of rapamycin (mTOR), we further illustrated the role of PI3K/Akt/mTOR signaling pathway in the process of CVB3-induced apoptosis.

Cell Death and Disease (2013) 4, e803; doi:10.1038/cddis.2013.331; published online 12 September 2013

Subject Category: Experimental Medicine

The phosphatidylinositol 3-kinase (PI3K) signaling pathway is an essential regulator of cellular proliferation, survival, metabolism and growth acting through disparate downstream effectors including the protein kinase $B$ (PKB or Akt) and mammalian target of rapamycin (mTOR) pathways, regulating the activity of host cap-dependent translation by integrating energy, amino acid and oxygen availability signals. ${ }^{1}$ Akt (also called $\mathrm{PKB}$ ) is a Ser/Thr kinase belonging to the AGC family (AMP/GMP kinases and protein kinase C) of kinases, ${ }^{2}$ of which activation depends on the phosphorylation of phosphatidylinositol (PI)-4,5-bisphosphate (Ptdlns $\left.(4,5) \mathrm{P}_{2}\right)$. It creates PI-3,4,5-triphosphate (Ptdlns $\left.(3,4,5) \mathrm{P}_{3}\right)$ at the plasma membrane mediated by PI3K and phosphatase and tensin homolog (PTEN, a phosphatase that counteracts the kinase action of PI3K). ${ }^{3,4}$ Akt modulates several cellular functions including metabolism, proliferation and survival, and exerts its regulatory effects through a wide-range of downstream effectors. The Akt kinase family is composed of three

\footnotetext{
${ }^{1}$ Department of Pediatrics, The Third Xiangya Hospital, Central South University, Changsha, China; ${ }^{2}$ Department of Organ Transplantation, The Third Xiangya Hospital, Central South University, Changsha, China; ${ }^{3}$ Department of the Center for Medical Experiments, The Third Xiangya Hospital, Central south University, Changsha, China and ${ }^{4}$ Materials Science and Engineering School, Nanyang Technological University, Singapore, Singapore

*Corresponding author: Z Yang, Department of Pediatrics, The Third Xiangya Hospital, Central South University, Tongzipo road 138, Changsha, China. Tel: 0731-88618205; Fax: 0731-88618498; E-mail: yang_zcr@126.com

Keywords: overexpression; 4EBP1; p70S6K; Akt; coxsackievirus b3; apoptosis

Abbreviations: PI3K, phosphatidylinositol 3-kinase; mTOR, mammalian target of rapamycin; Akt, protein kinase B, PKB; mTORC1, mTOR complex 1; mTORC2, mTOR complex 2; 4EBP1, elF4E-binding protein 1; p70S6K, p70S6 kinase; S473, serine 473; T308, threonine 308; TSC, tuberous sclerosis complex; CVB3, Coxsackievirus B3; PBS, phosphate-buffered saline; TEM, transmission electron microscope; CPE, cytopathic effect

Received 20.5.13; revised 04.8.13; accepted 06.8.13; Edited by A Stephanou
} 
members: Akt1, Akt2 and Akt3, which are consisted of a conserved $\mathrm{N}$-terminal pleckstrin homology domain, a central catalytic domain and a C-terminal regulatory hydrophobic motif, ${ }^{5}$ and share similar mechanisms of activation but exhibit distinct features. Akt1 and Akt2 are ubiquitously expressed, whereas Akt3 has a more limited tissue distribution such as the brain, testis, lung, heart, kidney, mammary gland and fat. ${ }^{6,7}$ In ZR-75 cells, Akt1 is the predominant isoform responsible for cell proliferation and survival; conversely, in IGROV1 cells, Akt2 has a major role in cell proliferation. ${ }^{8}$ Recent studies have shown that Akt1 has an important role in host anti-infection response via mediating the macrophage polarization and Akt2 contributes to the glucose availability and activation of apoptosis. ${ }^{9,10}$ Besides, dificiency of Akt3 in mice, but not Akt1 and Akt2, promotes foam cell formation and atherosclerosis. ${ }^{11}$

mTOR has two functionally distinct complexes: mTOR complex 1 (mTORC1) and mTOR complex 2 (mTORC2), which differ in their sensitivity to the drug rapamycin under normal conditions: mTORC1 is sensitive and mTORC2 is insensitive. When mTORC1 is active, it phosphorylates the elF4E-binding protein 1(4EBP1) and p70S6 kinase (S6K). 4EBP1 activation ensures the elF4E bind elF4G freely, thereby completing the elF4F complex on the $5^{\prime}$ cap and allowing cap-dependent translation to proceed. ${ }^{12}$ At the meantime, S6K phosphorylation promotes the formation of translation initiation complexes and enhances the translation of mRNAs consequently. ${ }^{13}$ However, a recent study has shown that manipulation of mTOR or Akt expression only regulates phosphorylation of S6K1 but not 4EBP1, and there is an alternative mTORindependent but PI3K-dependent regulation of 4EBP1. ${ }^{14} \mathrm{~S} 6 \mathrm{~K}$ deficiency, moreover, has been proved to protect against acute liver failure through inhibiting hepatocyte apoptosis. ${ }^{15}$

Apoptosis mediated via extrinsic or intrinsic pathways is essential for maintaining cellular homeostasis. Deregulation of apoptosis pathways contributes to diseases such as tumor, hepatocellular carcinoma and has been shown to be associated with chronic dilated cardiomyopathy and myocarditis. ${ }^{16,17}$ Owing to the strongest myocardial affinity, Coxsackievirus B3 (CVB3), a small, nonenveloped, positive-strand RNA Enterovirus in the Picornaviridae family, is thought to be one of the commonest viruses causing viral myocarditis (VMC). During the myocarditis process, CVB3 directly injures and kills infected cardiac myocytes. CVB3 infection leads to the phosphorylation of PKB/Akt on both Ser-473 and Thr-308 residues through a $\mathrm{PI} 3 \mathrm{~K}$-dependent mechanism. ${ }^{18}$ In addition, our previous work has demonstrated that both PI3K and mTOR signaling pathways participate in the CVB3-induced apoptosis. ${ }^{19}$ This present study highlights a pivotal role of the downstream factors of PI3K and mTOR having in the CVB3induced apoptosis, providing a deeper insight into the relationship between $\mathrm{PI} 3 \mathrm{~K} / \mathrm{Akt} / \mathrm{mTOR}$ signaling pathway and the CVB3-induced apoptosis.

\section{Results}

Establishment of stable cell lines overexpressing 4EBP1, p70S6K, Akt1 and Akt2, respectively. To identify the transfected cell lines, we determined the expressions of 4EBP1, p70S6k, Akt1, Akt2 and Myc tag by western blot analysis. Untransfected cells and cells containing the plasmid pcDNA3.1-myc-HisA(-)-4EBP1, pcDNA3.1-mycHisA(-)-p70S6K, pcDNA3.1-myc-HisA(-)-Akt1, pcDNA3. 1-myc-HisA(-)-Akt2 or the empty vector were seeded in six wells. After $24 \mathrm{~h}$ growth, cell lysates were collected. As we expected, compared with empty vector groups, 4EBP1, p70S6K, Akt1 and Akt2 were all overexpressed. Compared with Sham, the expression of Myc tag was detected at empty vector group (Figure 1).

Overexpression of 4EBP1, p70S6K, Akt1 or Akt2 promotes the CVB3-induced apoptosis and CPE. Recent studies have shown that CVB3-induced apoptosis is involved in the VMC pathogenesis, of which cytopathic effect (CPE) is a typical feature, characterized by degenerative changes in cell morphology including cell shrinkage, cell rounding and eventually cell detachment. Previous researches by our laboratory have demonstrated that inhibitions of PI3K- and mTOR-signaling pathway promote the CVB3-induced apoptosis and CPE. ${ }^{19}$ To further address this issue, we examined the roles of their downstream factors having in the CVB3induced apoptosis by flow cytometry. Cell lines containing the plasmid pcDNA3.1-myc-HisA(-)-4EBP1, pcDNA3.1-mycHisA(-)-p70S6K, pcDNA3.1-myc-HisA(-)-Akt1, pcDNA3. 1-myc-HisA(-)-Akt2 or the empty vector alone were infected with CVB3 and harvested at 3, 6, 12 and $24 \mathrm{~h} \mathrm{p.} \mathrm{i.} \mathrm{To} \mathrm{our}$ surprise, overexpression of 4EBP1, p70S6K, Akt1 or Akt2 promoted the CVB3-induced apoptosis. Moreover, apoptosis rate in Akt1 overexpression group was higher than others at the early stage after viral infection and decreased with the viral-infected time increasing, which was opposite to other groups (Figure 2).

Overexpression of p70S6K, Akt1 or Akt2 promotes viral mRNA expression but blocks the VP1 expression, which is opposite to the 4EBP1-transfected groups. It has been demonstrated that CVB3 infection can lead to the phosphorylation of PKB/Akt through a PI3K-dependent mechanism, which stimulates $\mathrm{mTOR}$ and its downstream factors contributing to host defense against CVB3 infection in return. ${ }^{18,20}$ Our previous works have shown that LY294002 and rapamycin could stimulate viral mRNA and VP1 expressions, respectively, illustrating a fundamental role for the PI3K and mTOR pathways in CVB3 pathogenesis. To further characterize the change of viral replication when this pathway was overexpressed, cells containing the plasmid pcDNA3.1-myc-HisA(-)-4EBP1, pcDNA3.1-mycHisA(-)-p70S6K, pcDNA3.1-myc-HisA(-)-Akt1, pcDNA3.1myc-HisA(-)-Akt2 or the empty vector alone were infected with CVB3. By means of immunofluorescence, we found that with the infected time increasing, VP1 expressions were getting stronger, which were increasing sharply at $24 \mathrm{~h} \mathrm{p}$. i. At the meanwhile, VP1 expressions were found both in the nuclei and cytoplasm in the transfected cells. At the early stage after viral infected, cytoplasm was the main site of VP1 expression, but with the infected time growing, it transferred from the endoplasmic reticulum to the nuclei following by the increased expressions. Besides, cell lysates were collected at $3,6,12$ and $24 \mathrm{~h}$ p. i., and viral mRNA and capsid protein VP1 expressions were determined by real-time fluorescence quantitative PCR, Western blot analysis and 
a
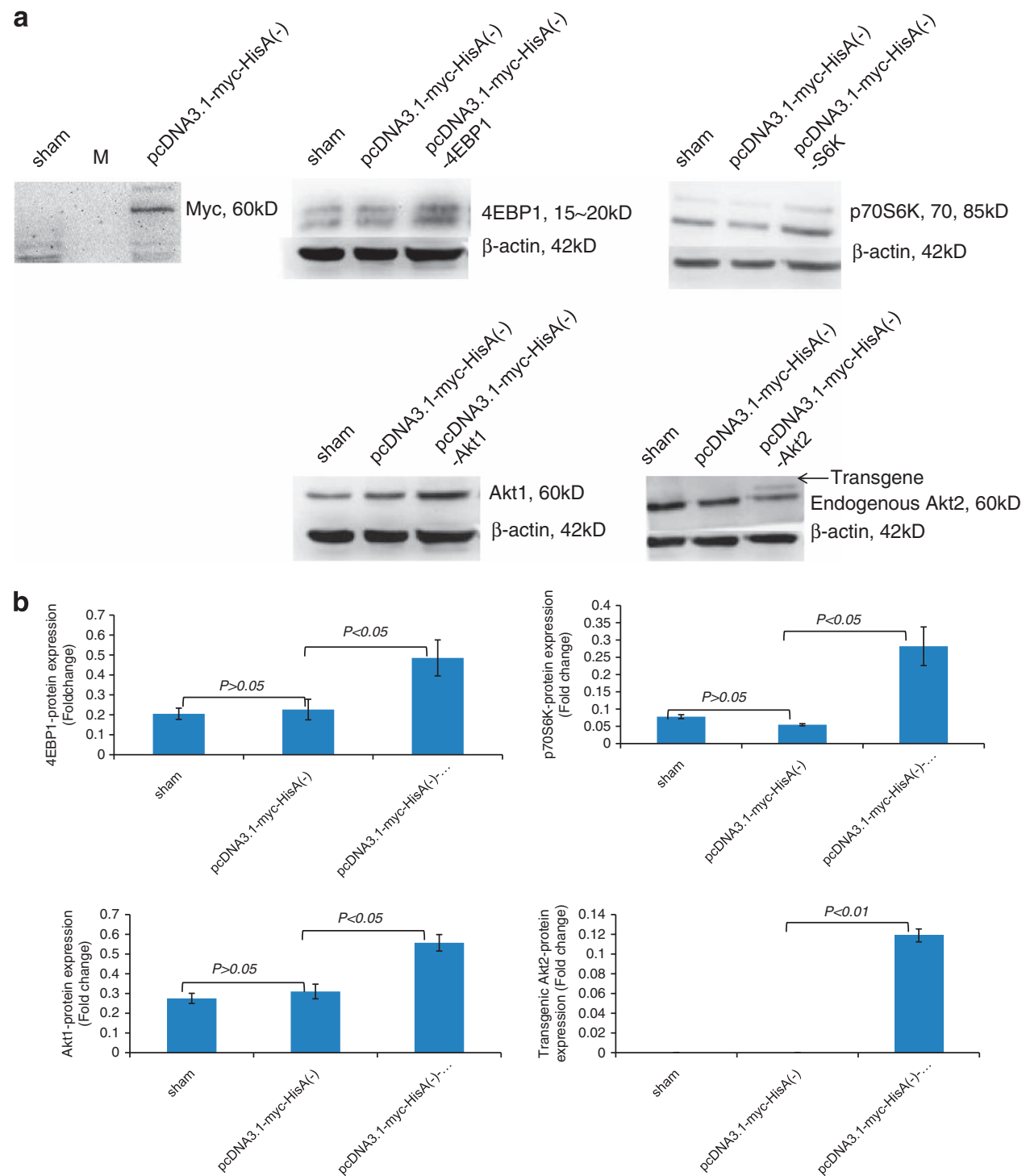

Figure 1 Establishment of stable cell lines overexpressing 4EBP1, p70S6K, Akt1 and Akt2, respectively. The expressions of 4EBP1, p70S6K, Akt1, Akt2 and Myc tag were determined by western blot analysis (a), and these same samples (except Myc tag) were immunoblotted with an antibody to $\beta$-actin to illustrate equal protein loading (mean \pm S.E.; $n=3$ ) (b). Compared with Sham, Myc tag expression was detected at empty vector group in which 4EBP1, p70S6K, Akt1 and Akt2 expressions were no significant differences $(P>0.05)$. Compared with empty vector group, 4EBP1, p70S6K, Akt1 and Akt2 expressions in corresponding transfected groups were significant differences $(P<0.05)$

Immunofluorescence, respectively. We found that overexpression of 4EBP1 just promoted viral mRNA expression at $3 \mathrm{~h} \mathrm{p}$. i., while stimulated the VP1 expression at 6,12 and $24 \mathrm{~h}$ p. i. At the meantime, expressions of viral mRNA increased in groups overexpressing of p70S6K, Akt1 or Akt2 whose VP1 expressions were stimulated at 6 and $12 \mathrm{~h} \mathrm{p}$. i. but decreased at $24 \mathrm{~h} \mathrm{p}$. i., which was an unexpected result for us. At $3 \mathrm{~h} \mathrm{p}$. i., there was no VP1 expression detected by western bolt analysis, in accordance with an earlier study. ${ }^{21}$ Under the observation of transmission electron microscopy (TEM), the cellular and nuclear morphology of infected cells changed a lot. We could find nuclear shrinkage, swelling or fragmentation, and mitochondria swelling, organelles fragmentation or even cell necrosis. Moreover, chromatin was highly concentrated and a large amount of virus particles and inclusions could be found in the cytoplasm and nucleus (Figure 3, Table 1).

CVB3-induced Bim activation at the early stage is blocked by the overexpression of 4EBP1, p70S6K or Akt2 while promoted by overexpression of Akt1. Being a pro-apoptosis factor, Bim is activated via the JNK and p38 kinase pathways and $\mathrm{CHOP}$ during endoplasmic reticulum (ER) stress, ${ }^{22,23}$ which can be stimulated by viral infection, ${ }^{24,25}$ and has been reported to directly link ER stress to mitochondrial apoptosis in cells expressing mSOD1 ${ }^{26}$ In this study, we further determined the Bim mRNA and protein expression by real-time fluorescence quantitative PCR and western blot analysis using CVB3-infected cells containing the plasmid pcDNA3.1-myc-HisA(-)-4EBP1, 
a

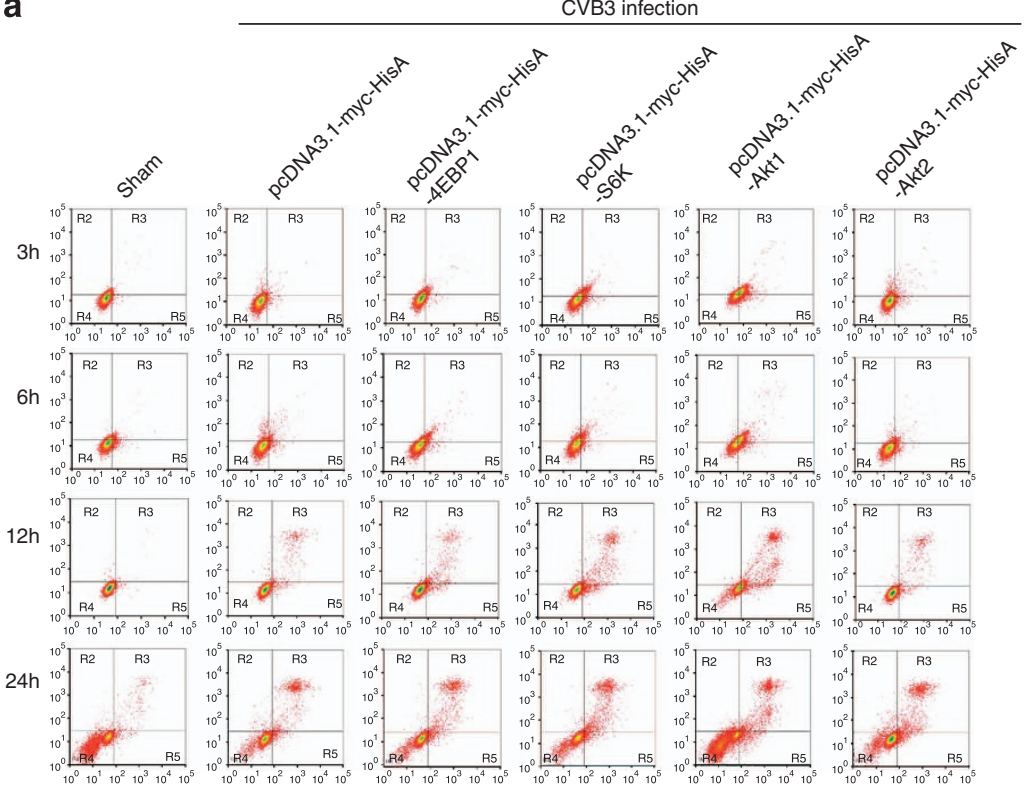

b

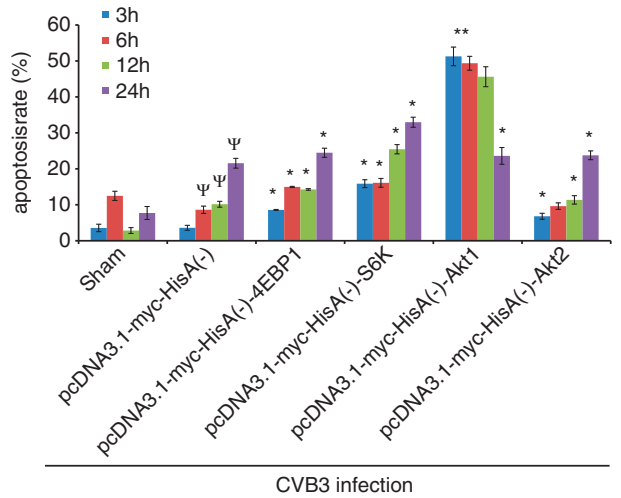

C

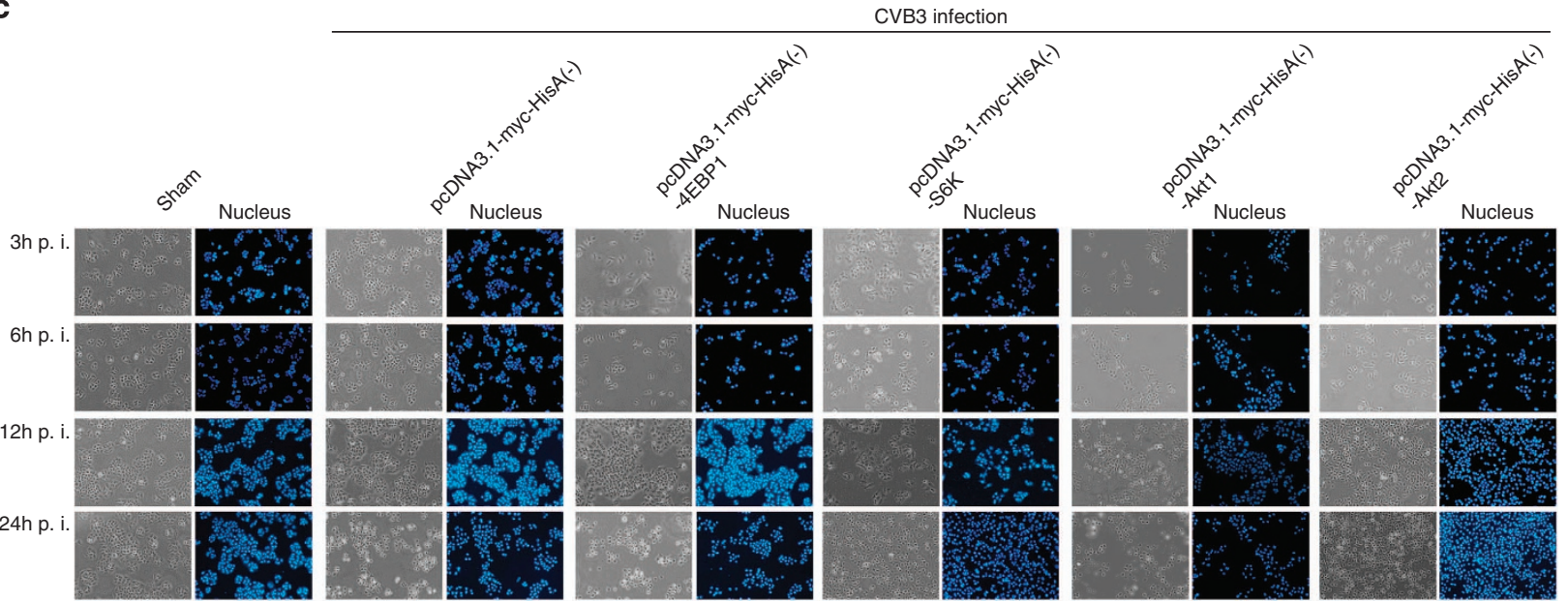

Figure 2 Overexpression of 4EBP1, p70S6K, Akt1 or Akt2 promotes the CVB3-induced apoptosis and CPE. Cell lines containing the above mentioned plasmids were infected with CVB3. Collected at 3, 6, 12 and $24 \mathrm{~h} \mathrm{p}$. i., apoptosis was determined by flow cytometry immediately after dyed by Annexin-V-FITCand PI. (mean \pm S.E.; $n=3$ ) (a). Compared with Sham, apoptosis rate in empty vector groups at 6,12 and $24 \mathrm{~h} p$. i. were significant differences $\left({ }^{\psi} P<0.05\right)$. Compared with empty vector groups, except in the Akt2 group at $6 \mathrm{~h} \mathrm{p}$. i., the apoptosis rate were significant differences $\left({ }^{*} P<0.05,{ }^{*} P<0.05\right)(\mathbf{b})$. Representative phase contrast microscopy of untransfected HeLa cells and cell lines containing the above plasmids at $3,6,12$ and $24 \mathrm{~h} \mathrm{p}$. i., there was no obvious CPE in pictures at 3 and $6 \mathrm{~h} \mathrm{p}$. i., while it could be seen at 12 and $24 \mathrm{~h} \mathrm{p}$. i., moreover, CPE at $24 \mathrm{~h} \mathrm{p}$. i. was more serious than that at $12 \mathrm{~h} \mathrm{p}$. i., which we could hardly find a normal cell at $24 \mathrm{~h} \mathrm{p}$. i., and most of the nuclei were swelling, shrinking or crushing (c)

pcDNA3.1-myc-HisA(-)-p70S6K, pcDNA3.1-myc-HisA(-)Akt1, pcDNA3.1-myc-HisA(-)-Akt2 or the empty vector alone. We found that CVB3-induced Bim activation happened at 3 and $6 \mathrm{~h} \mathrm{p}$. i., which could be promoted by the overexpression of Akt1 but attenuated by the overexpression of 4EBP1. Yet, the simulation by Akt1 overexpression did not last a long time. At 12 and $24 \mathrm{~h} \mathrm{p}$. i., overexpression of Akt1 turned to decrease the Bim expression, which was also decreased by the overexpression of 4EBP1, p70S6K or Akt2. It was noteworthy that although the overexpression of Akt1promoted the expressions of Bim protein at 3 and $6 \mathrm{~h}$ p. i., it inhibited the expressions of Bim mRNA throughout the infection process (Figure 4, Table 2).
Overexpression of 4EBP1 or p70S6K blocks the ability of CVB3-induced Bax activation, which was promoted by the overexpression of Akt1. Bax, the major core of the intrinsic apoptosis pathway at the mitochondria, is directly mediated by Bim and Akt activation. However, a recent study has shown that apoptosis induced by reovirus infection is independently of the proapoptotic proteins Bax and Bak. ${ }^{27}$ Our previous work has revealed that PI3K and mTOR pathways take part in apoptosis via mediating the proapoptotic factors including Bax. Therefore, to further investigate the mechanism, Bax mRNA and protein were analyzed by real-time fluorescence quantitative PCR and western blot analysis using CVB3-infected cells containing the 
plasmid pcDNA3.1-myc-HisA(-)-4EBP1, pcDNA3.1-mycHisA(-)-p70S6K, pcDNA3.1-myc-HisA(-)-Akt1, pcDNA3.1myc-HisA(-)-Akt2 or the empty vector alone and cell lysates were collected at 3, 6, 12 and $24 \mathrm{~h}$ p. i. CVB3-induced Bax activation was peaked at $12 \mathrm{~h}$ p. i. when overexpression of p70S6K or Akt1 made it decrease. At $24 \mathrm{~h}$ p. i., however, CVB3-induced Bax activation attenuated, which was provoked by the overexpression of Akt1 but further blocked by the 4EBP1 overexpression. It was also noteworthy that similar to the effect of Bim, overexpression of Akt1 inhibited the expressions of Bax mRNA expression during the infection course (Figure 5, Table 3).

Overexpression of 4EBP1 or p70S6k provokes the CVB3-induced procaspase-9 self-cleavage, which is blocked by the overexpression of Akt1 or Akt2. Caspase, a family of cysteine protease, is the common mediator of apoptosis induced by various stimuli. Although a recent study has reported that there is a caspase-independent apoptosis signaling pathway, ${ }^{28}$ as a classical proapoptotic family, caspase has a major role both in the intrinsic and extrinsic apoptosis pathways, of which caspase3 contributes to the apoptosis execution, whereas caspase- 9 participates in the apoptosis origination. In this study, we determined the caspase- 9 activation by real-time fluorescence quantitative PCR and western blot analysis using cells containing the plasmid pcDNA3.1-myc-HisA(-)-4EBP1, pcDNA3.1-myc-HisA(-)-p70S6K, pcDNA3.1-myc-HisA(-)Akt1, pcDNA3.1-myc-HisA(-)-Akt2 or the empty vector alone to further illustrate the role of $\mathrm{PI} 3 \mathrm{~K} / \mathrm{mTOR}$ pathway in the viral-induced apoptosis. Overexpression of Akt1 stimulated the expressions of procaspase- 9 as well as overexpression of Akt2, blocked the CVB3-induced self-cleavage, which was promoted by the overexpression of 4EBP1 or p70S6K. Therefore, as previously stated, our results revealed an approximate decrease in the level of procaspase- 9 concurrently with an increase in cleaved caspase- 9 protein (Figure 6, Table 4).

CVB3-induced caspase-3 self-cleavage is stimulated by the overexpression of 4EBP1 but decreased by the overexpression of Akt1. Caspase-3 is an essential executioner of apoptosis, activating by the upstream apoptosis initiators such as caspase-9/8. In this research, caspase-3 expression was determined by real-time fluorescence quantitative PCR and western blot analysis, making use of the HeLa cells containing the plasmid pcDNA3.1-mycHisA(-)-4EBP1, pcDNA3.1-myc-HisA(-)-p70S6K, pcDNA3.1myc-HisA(-)-Akt1, pcDNA3.1-myc-HisA(-)-Akt2 or the empty vector alone. At the early stage of infection, overexpression
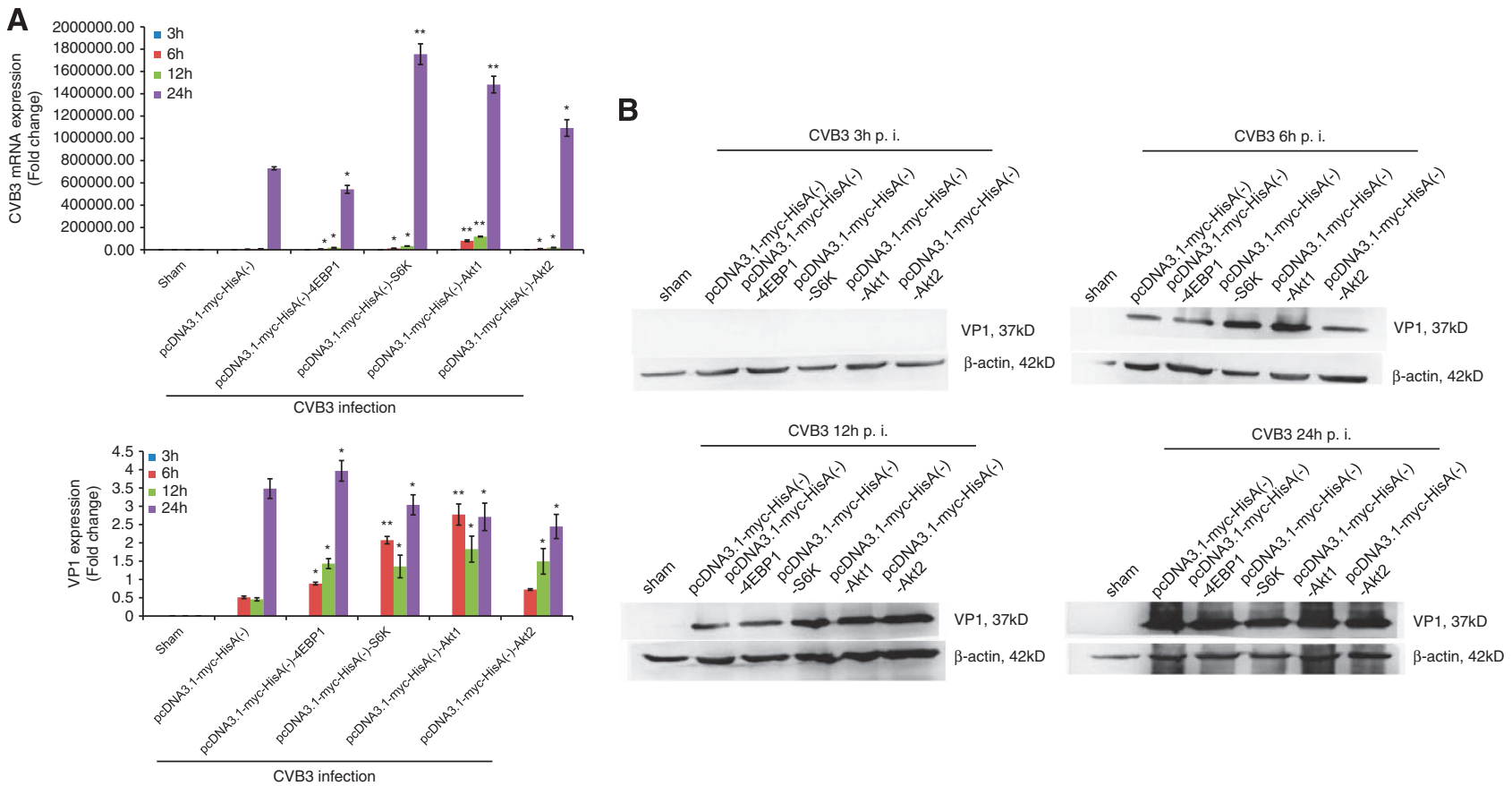

Figure 3 Overexpression of p70S6K, Akt1 or Akt2 promotes viral mRNA expression but blocks the VP1 expression, which is opposite to the 4EBP1-transfected groups. Cell lines containing the above mentioned plasmids were infected with CVB3. With the infected time growing, VP1 expressions were getting stronger, which were increasing sharply at $24 \mathrm{~h} \mathrm{p}$. i.. In the transfected cells, VP1 expressions were found both in the nuclei and cytoplasm. At the early time after viral infected, cytoplasm was the main site of VP1 expression, but with the infected time growing, it transferred from the endoplasmic reticulum to the nuclei (C). Cell lysates were collected at $3,6,12$ and $24 \mathrm{~h} \mathrm{p}$. i., CVB3 mRNA and VP1 activities were determined by semi-quantitative PCR and western blot analysis (B). mRNA expressions were determined by real-time fluorescence quantitative PCR (mean \pm S.E.; $n=3$ ) and normalized to internal control- $\beta$-actin, which was arbitrarily set to a value of 1.0 , and these same samples were immunoblotted with an antibody to $\beta$-actin to illustrate equal protein loading (mean \pm S.E.; $n=3)(\mathbf{A})$. Compared with empty vector groups, viral mRNA expressions in all groups were significant differences $\left({ }^{\star} P<0.05,{ }^{\star}{ }^{\star} P<0.01\right)$, except in Akt2 group at $6 \mathrm{~h} \mathrm{p}$. i., VP1 expressions in other transfected groups were significant differences $\left({ }^{\star} P<0.05\right.$ $\left.{ }^{\star *} P<0.01\right)$. CVB3 replications were observed by TEM (D): Figures a and $\mathrm{a}^{\prime}$-sham group, the morphology and structure of cell and nucleus were generally normal and the nucleolus was full. Figures $b, b^{\prime}, c, c^{\prime}, d, d^{\prime}, e, e^{\prime}$ and $f, f^{\prime}$ - containing the above mentioned plasmids were all infected with CVB3, the cellular and nuclear morphology of cells changed irregularly. We could find nuclear shrinkage, swelling or fragmentation, and mitochondria swelling, organelles fragmentation, or even cell necrosis. Besides, there are a lot of virus particles and inclusions in the cytoplasm, perinuclear space and nucleus (red arrows) 
C

CVB3 infection

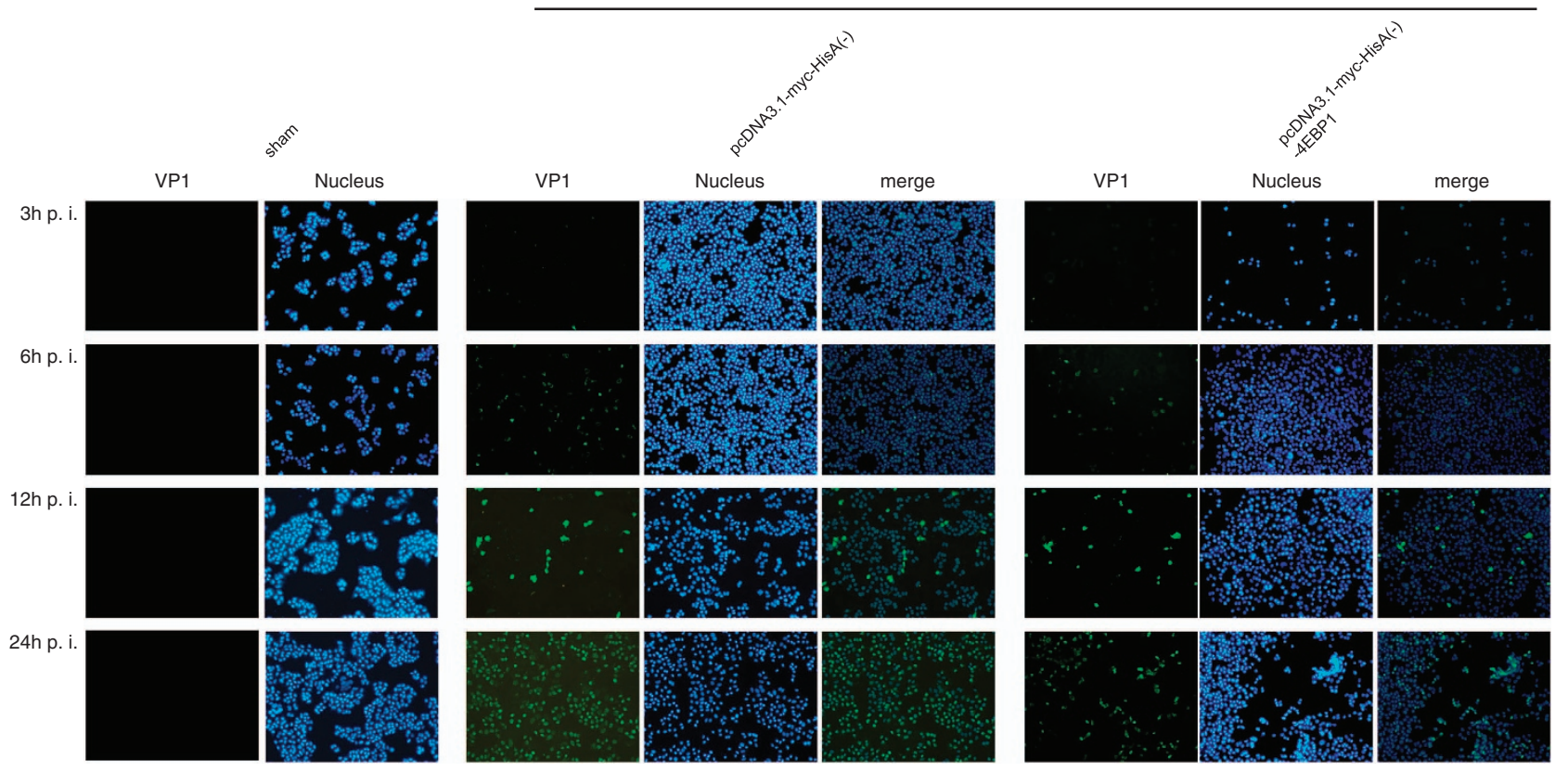

CVB3 infection

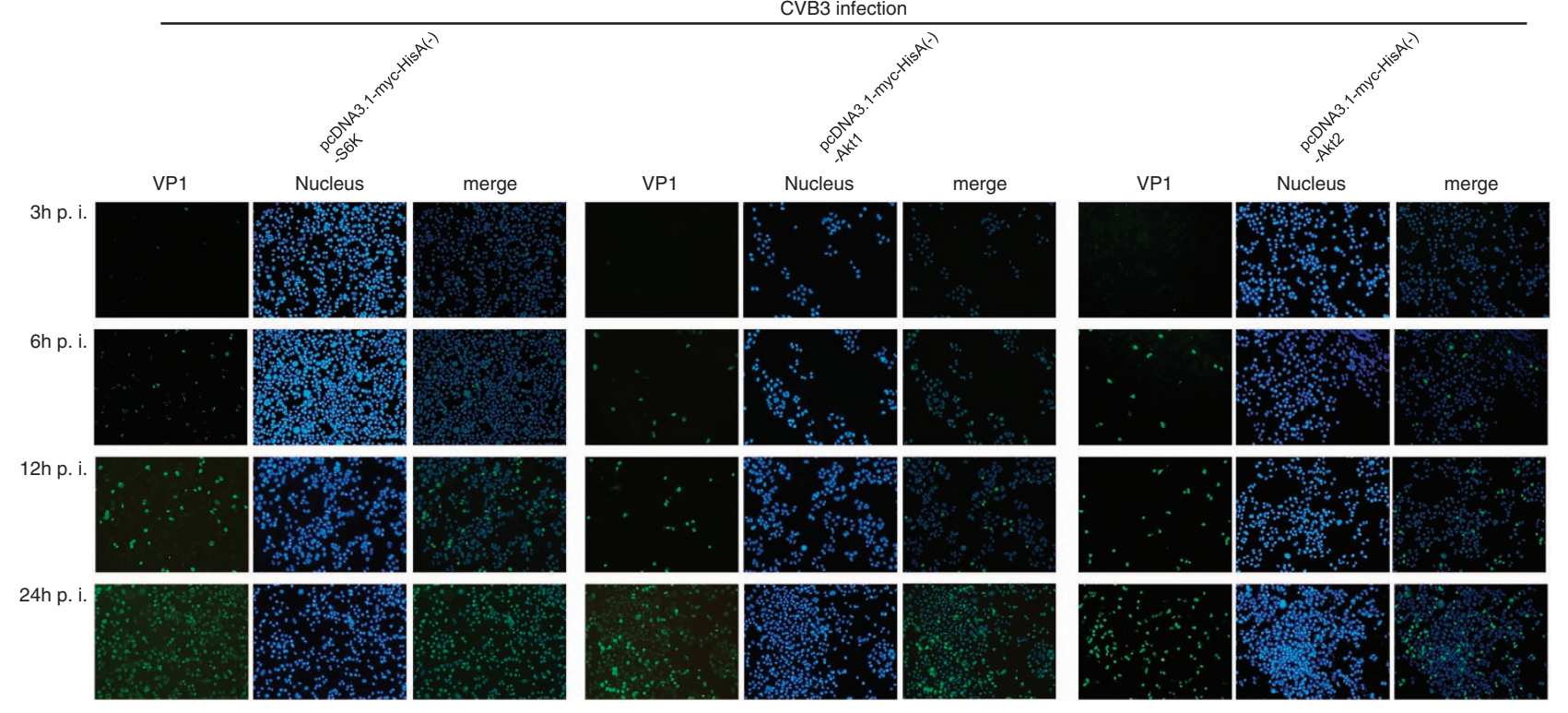

Figure 3 (Continued)

of 4EBP1, Akt1 or Akt2 promoted the caspase-3 expression when cleaved caspase- 3 was not found. Along with the infection time increasing, the apoptosis was aggravated, followed by the increased self-cleavage that was further stimulated by the overexpression of 4EBP1, whereas decreased by the overexpression of Akt1, which inhibited the mRNA expression at $24 \mathrm{~h}$ p. i. (Figure 7, Table 5).

\section{Discussion}

Apoptosis, essential for normal development and tissue homeostasis in multicellular organisms, is a conserved cell death mechanism regulated by the balance between pro- apoptotic and anti-apoptotic factors. As one of the most important mediators in cell growth, proliferation, differentiation and angiogenesis, protein synthesis and degradation, PI3K/ mTOR signaling pathway has gained much recent attention that has been also demonstrated to be involved in the apoptosis, of which the mTOR-/elF4E-signaling pathway, moreover, has been proved to be utilized by CVB3 to promote its replication during the pathogenesis of $\mathrm{VMC}^{16}$ In this present study, we have shown that the overexpression of 4EBP1, p70S6K, Akt1 or Akt2 promotes the CVB3-induced apoptosis and CPE. At the same time, overexpression of 4EBP1 reduces the viral mRNA expression yet stimulate the activations of VP1, while the others promote the viral mRNA expression but decrease the VP1 
D
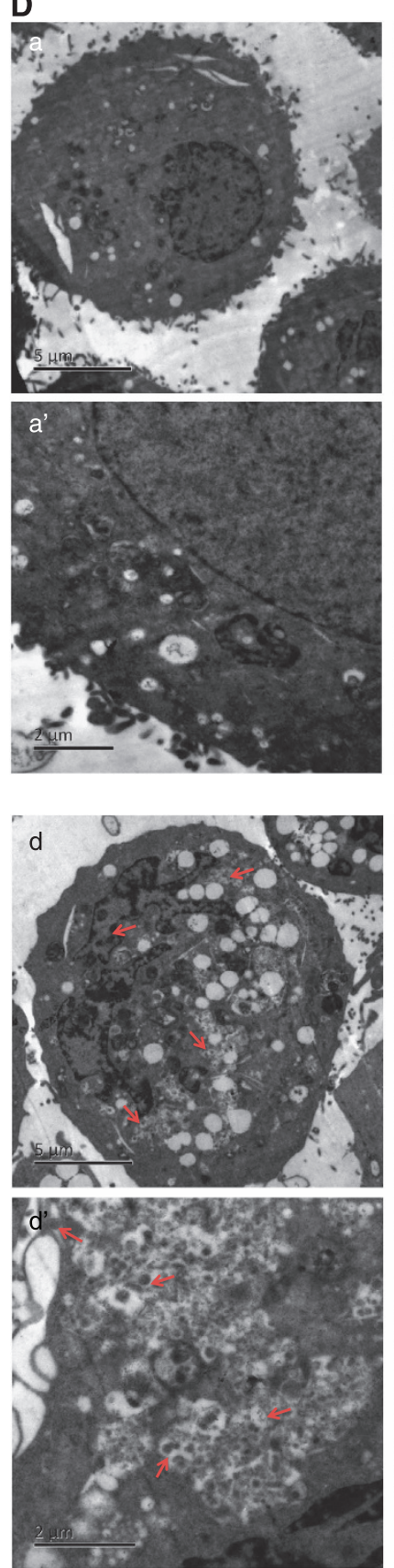
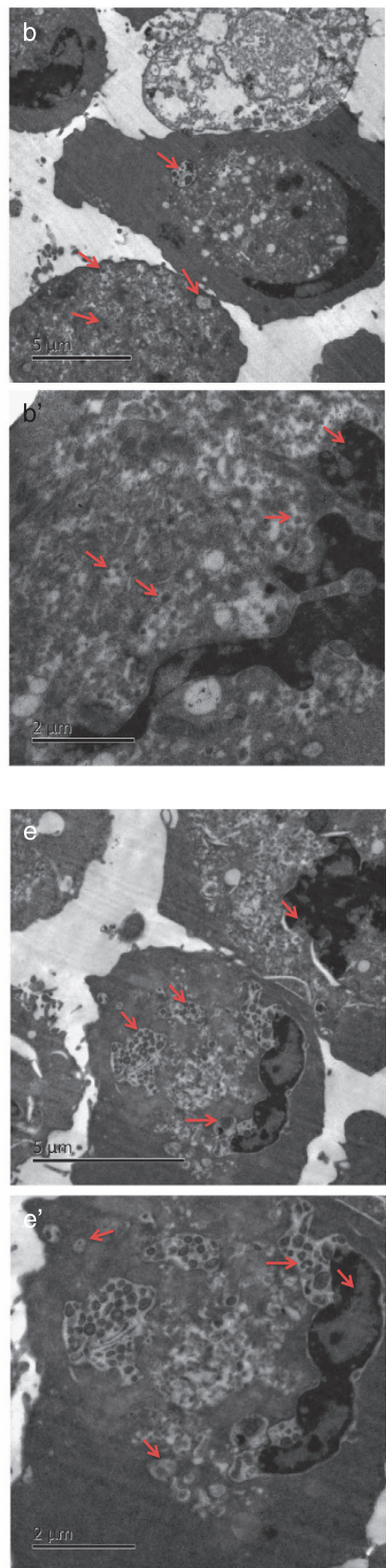
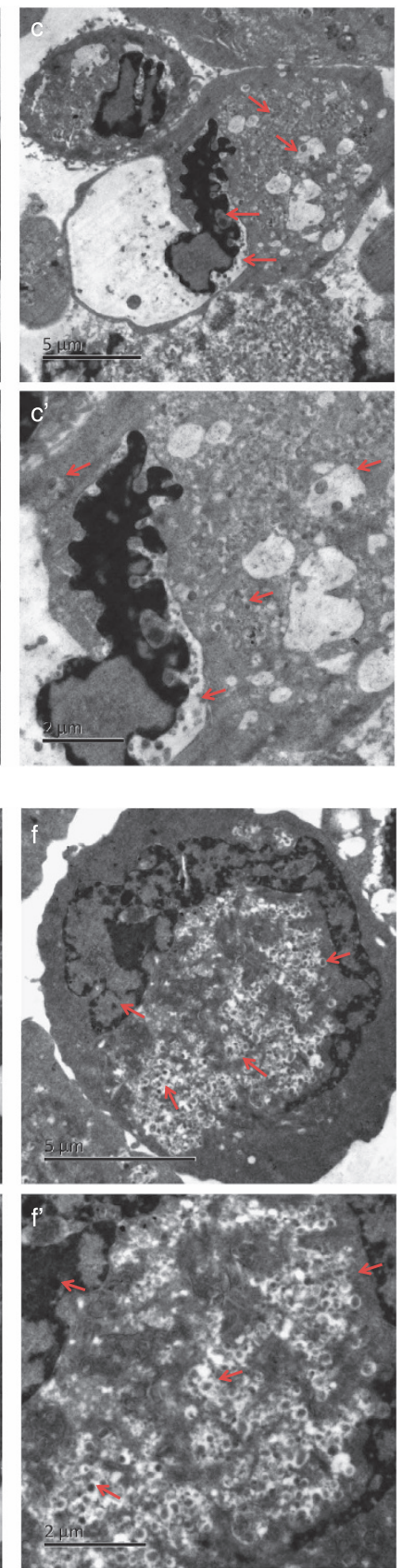

Figure 3 (Continued)

Table 1 The CVB3 mRNA expression $\left(2^{-\Delta C t}\right.$, mean \pm S.E.; $\left.n=3\right)$

\begin{tabular}{|c|c|c|c|c|c|c|}
\hline & Sham & pc + CVB3 & 4EBP1 + CVB3 & S6K + CVB3 & Akt1 + CVB3 & Akt2 + CVB3 \\
\hline $\begin{array}{l}3 \text { h p. i. } \\
6 \text { h p. i. } \\
12 \text { h p. i. } \\
24 \text { h p. i. }\end{array}$ & $\begin{array}{l}0 \pm 0 \\
0 \pm 0 \\
0 \pm 0 \\
0 \pm 0\end{array}$ & $\begin{array}{c}23.06 \pm 4.46 \\
4372.28 \pm 742.84 \\
8431.51 \pm 844.38 \\
730796.03 \pm 13620.87\end{array}$ & $\begin{aligned} 40.89 & \pm 6.89 \\
6478.00 & \pm 630.51 \\
18181.02 & \pm 2724.10 \\
542307.14 & \pm 35645.72\end{aligned}$ & $\begin{array}{c}101.16 \pm 10.25 \\
12459.67 \pm 2140.96 \\
33511.47 \pm 1651.02 \\
1755201.40 \pm 92547.18\end{array}$ & $\begin{array}{c}300.61 \pm 17.86 \\
80612.13 \pm 7833.34 \\
118425.37 \pm 2887.50 \\
1482590.79 \pm 74868.23\end{array}$ & $\begin{aligned} 71.30 & \pm 6.60 \\
9677.88 & \pm 115.17 \\
19813.57 & \pm 1863.33 \\
1092578.57 & \pm 74599.21\end{aligned}$ \\
\hline
\end{tabular}

Abbreviations: CVB3, Coxsackievirus B3; 4EBP1, elF4E-binding protein 1; p. i., postinfection; S6K, p70S6 kinase

expression at the late stage of infection. Together with our discoveries that the expressions of pro-apoptosis factors in $\mathrm{Bcl}-2$ and caspase families change dynamically in stable cells lines containing different plasmids with the infected time increasing, our data further illustrate that the downstream signal molecules of PI3K and mTOR promote the CVB3-induced 


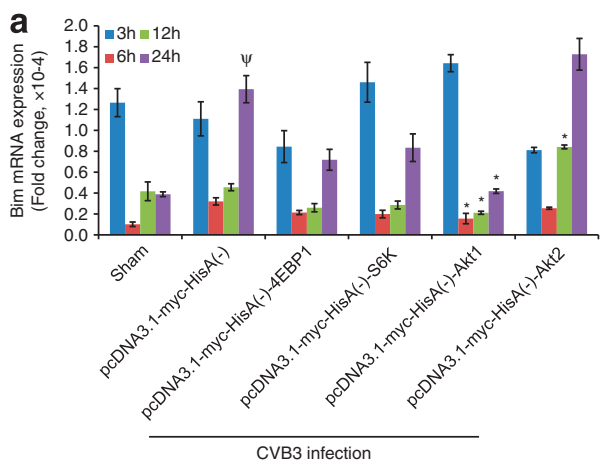

b

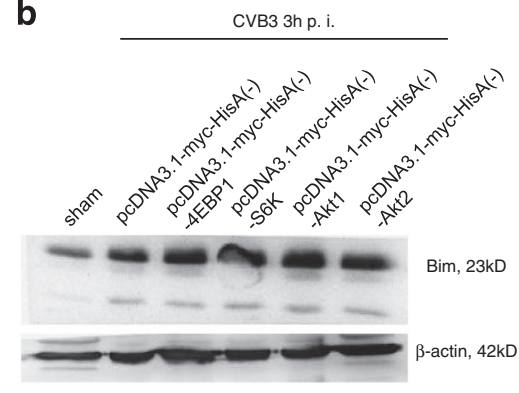

CVB3 $12 \mathrm{~h} \mathrm{p.} \mathrm{i.}$

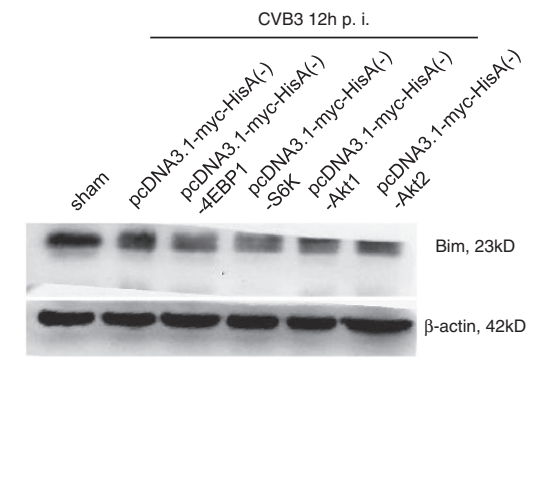

CVB3 6h p. i.

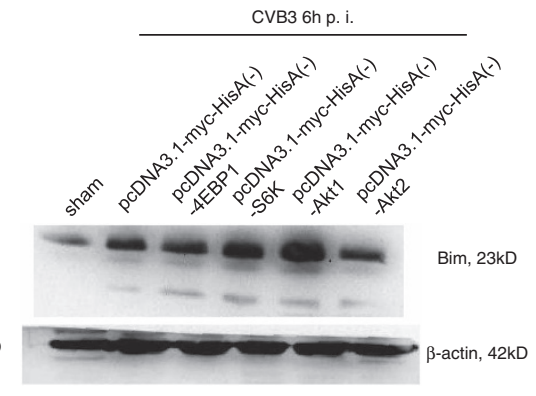

CVB3 $24 h$ p. i.

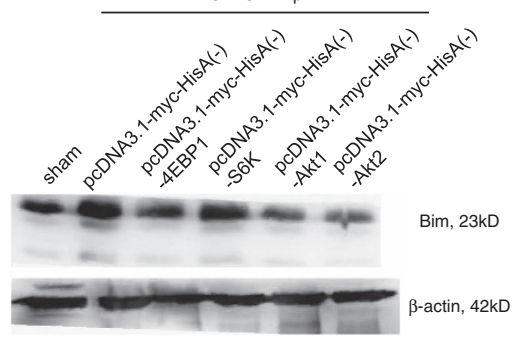

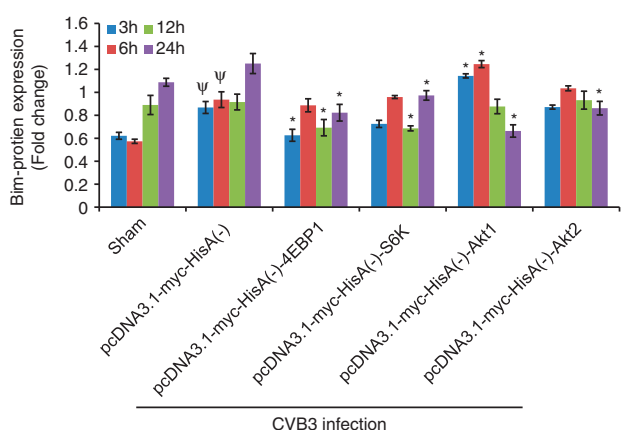

Figure 4 CVB3-induced Bim activation at the early stage is blocked by the overexpression of 4EBP1, p70S6K or Akt2 while promoted by overexpression of Akt1. Cell lines containing the above mentioned plasmids were infected with CVB3. Cell lysates were harvested at 3, 6, 12 and $24 \mathrm{~h} \mathrm{p}$. i. and Bim expression was determined by semiquantitative PCR and Western blot analysis (a). mRNA expressions were determined by real-time fluorescence quantitative PCR (mean \pm S.E.; $n=3$ ) and normalized to internal control $-\beta$-actin, which was arbitrarily set to a value of 1.0 , and these same samples were immunoblotted with an antibody to $\beta$-actin to illustrate equal protein loading (mean \pm S.E.; $n=3$ ) (b). Compared with empty vector groups, mRNA expressions in Akt1 and Akt2 groups were significant differences ( ${ }^{*} P<0.05$ ); except in 4EBP1 group at $6 \mathrm{~h} \mathrm{p}$. i., in p70S6K group at 3 and $6 \mathrm{~h} \mathrm{p}$. i., in Akt1 group at $12 \mathrm{~h} \mathrm{p}$. i. and in Akt2 group at $3,6 \mathrm{~h} \mathrm{p}$. i., protein expressions in other transfected groups were significant differences $\left({ }^{*} P<0.05\right)$. Compared with Sham, mRNA expressions in empty vector group at 3 and $24 \mathrm{~h} \mathrm{p}$. i. were significant differences $\left({ }^{\psi} P<0.05\right)$; protein expressions in empty vector group at 3 and $6 \mathrm{~h} \mathrm{p}$. i. were significant differences $\left({ }^{\psi} P<0.05\right)$

Table 2 The Bim mRNA expression $\left(2^{-\Delta C t}\right.$, mean \pm S.E.; $\left.n=3,1 \times 10^{-4}\right)$

\begin{tabular}{lccccrc}
\hline & Sham & pc + CVB3 & 4EBP1 + CVB3 & S6K + CVB3 & Akt1 + CVB3 & Akt2 + CVB3 \\
\hline 3h p. i. & $1.27 \pm 0.13$ & $1.11 \pm 0.16$ & $0.84 \pm 0.15$ & $1.46 \pm 0.19$ & $1.64 \pm 0.08$ & $0.81 \pm 0.03$ \\
6h p. i. & $0.10 \pm 0.02$ & $0.32 \pm 0.03$ & $0.21 \pm 0.02$ & $0.20 \pm 0.04$ & $0.16 \pm 0.05$ & $0.26 \pm 0.01$ \\
12 p. i. & $0.42 \pm 0.09$ & $0.46 \pm 0.03$ & $0.26 \pm 0.04$ & $0.29 \pm 0.04$ & $0.21 \pm 0.02$ & $0.84 \pm 0.02$ \\
24 h p. i. & $0.39 \pm 0.02$ & $1.39 \pm 0.13$ & $0.72 \pm 0.10$ & $0.83 \pm 0.13$ & $0.42 \pm 0.02$ & $1.73 \pm 0.15$ \\
\hline
\end{tabular}

Abbreviations: CVB3, Coxsackievirus B3; 4EBP1, elF4E-binding protein 1; p. i., postinfection; S6K, p70S6 kinase

apoptosis via different mediation mechanisms. In addition, there was another interesting result that apoptosis rate in Sham group at $6 \mathrm{~h} \mathrm{p}$. i. was higher than that in empty vector group. It is probably due to the CVB3 that may activate the PI3K/Akt pathway in order to restrain apoptosis, and thus provide shortterm cellular survival during viral replication. ${ }^{29}$

Akt is the most critical substrate of the PI3K and its activation depends on the PI3K-mediated reversible conversion of Ptdlns $(4,5) \mathrm{P}_{2}$ to $\mathrm{Ptdlns}(3,4,5) \mathrm{P}_{3}$. Akt has a pivotal role in regulating cell survival by phosphorylation and inactivation of a list of important proapoptotic molecules including Bcl-2-antagonist of cell death, procaspase-9 and the FOXO transcription factors, thereby blocking or preventing programmed cell death. ${ }^{8}$ It is commonly held the concepts that Akt is an anti-apoptosis factor. Besides, a recent study has reported that Akt1 activation may prevent apoptosis through upregulating of the survivin. ${ }^{30}$ In the present study, however, we reported that overexpression of Akt1 or Akt2 promoted the CVB3-induced apoptosis and CPE. Contrary to the previous study, the apoptosis was peaking at $3 \mathrm{~h} \mathrm{p}$. i. and slowly attenuated with the infected time increasing. An early study has reported that CVB3 infection enhances PI3K phosphorylation and then activates Akt at Thr-308 to increase the viability of infected host cells in order for viral replication to take place. ${ }^{18}$ Meanwhile, PI3K phosphorylation directly activates mTORC2 phosphorylating Akt at Ser-473, which results in the complete activation of Akt together with phosphorylation at T308. ${ }^{14}$ In addition, overexpression of Akt provides this pathway more substrates. Therefore, mTORC1 is fully activated and then phosphorylates 4EBP1 and p70S6K, maintaining cap-dependent translation. Consequently, the viral replication is further activated. As we shown in this study, overexpression of Akt1 or Akt2 provoked the VP1 expression at the early stage of infection, yet decreased along with the infection time increasing. As above mentioned, mTORC2 is the upstream signal molecular of mTORC1, 

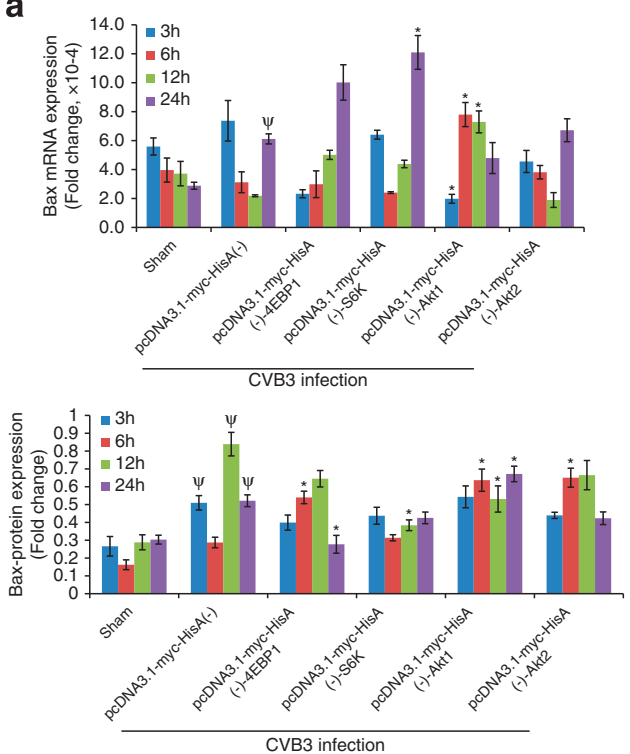

b

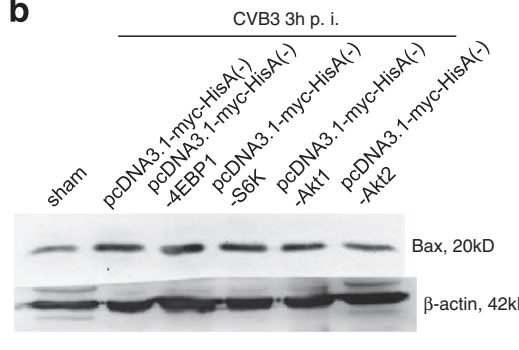

CVB3 $12 \mathrm{~h} \mathrm{p.} \mathrm{i.}$

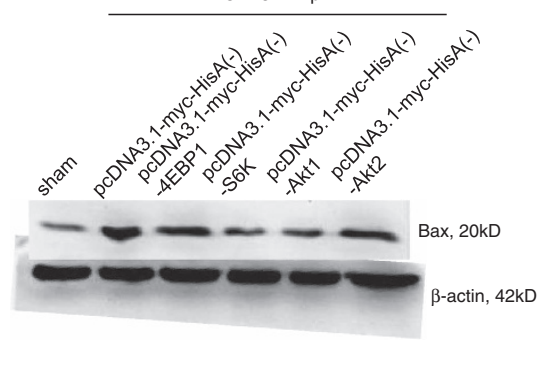

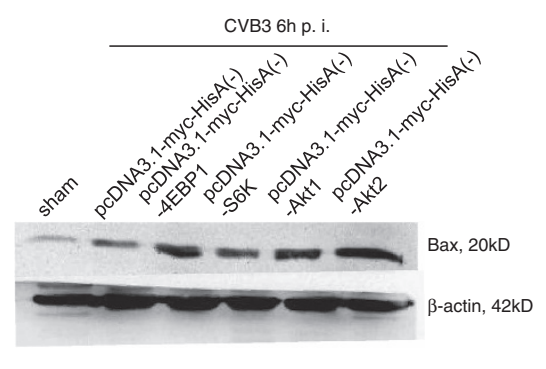

CVB3 24h p. i.

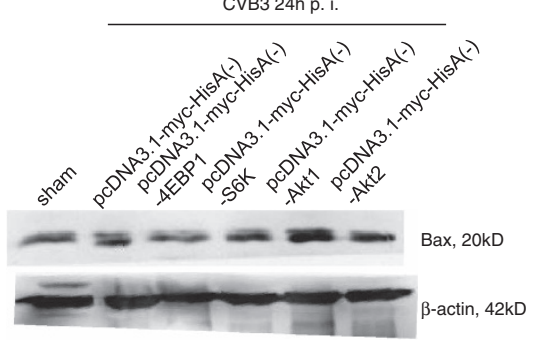

Figure 5 Overexpression of 4EBP1 or p70S6K blocks the ability of CVB3-induced Bax activation which was promoted by the overexpression of Akt1. Cell lines containing the above mentioned plasmids were infected with CVB3. Cell lysates were harvested at 3, 6, 12 and $24 \mathrm{~h} \mathrm{p}$. i. and Bax activity was determined by semi-quantitative PCR and Western blot analysis (b). mRNA expressions were determined by real-time fluorescence quantitative PCR (mean \pm S.E.; $n=3$ ) and normalized to internal control- $\beta$-actin, which was arbitrarily set to a value of 1.0, and these same samples were immunoblotted with an antibody to $\beta$-actin to illustrate equal protein loading (mean \pm S.E.; $n=3$ ) (a). Compared with empty vector groups, mRNA expressions in Akt1 group at 3,6 and $12 \mathrm{~h} \mathrm{p.} \mathrm{i.,} \mathrm{in} \mathrm{p70S6K} \mathrm{group} \mathrm{at} 24 \mathrm{~h} \mathrm{p}$. i. were significant differences ( ${ }^{*} P<0.05$ ); protein expressions in 4EBP1 group at 6, $24 \mathrm{~h} \mathrm{p}$. i., in p70S6K group at $12 \mathrm{~h} \mathrm{p}$. i., in Akt1 group at 6, 12, $24 \mathrm{~h} \mathrm{p}$. i. and in Akt2 group at $6 \mathrm{~h} \mathrm{p}$. i. were significant differences ( $\left.{ }^{\star} P<0.05\right)$. Compared with Sham, protein expressions in empty vector group at 3,12 and $24 \mathrm{~h} \mathrm{p}$. i. were significant differences $\left({ }^{\psi} P<0.05\right)$

Table 3 The Bax mRNA expression $\left(2^{-\Delta \mathrm{Ct}}\right.$, mean \pm S.E. $\left.n=3,1 \times 10^{-4}\right)$

\begin{tabular}{lccrrrr}
\hline & Sham & pc + CVB3 & 4EBP1 + CVB3 & S6K + CVB3 & Akt1 + CVB3 & Akt2 + CVB3 \\
\hline 3h p. i. & $5.59 \pm 0.59$ & $7.37 \pm 1.40$ & $2.33 \pm 0.28$ & $6.41 \pm 0.31$ & $1.98 \pm 0.31$ \\
6h p. i. & $3.97 \pm 0.83$ & $3.12 \pm 0.72$ & $2.98 \pm 0.92$ & $2.41 \pm 0.06$ & $7.80 \pm 0.83$ & $4.56 \pm 0.76$ \\
12h p. i. & $3.72 \pm 0.84$ & $2.19 \pm 0.06$ & $5.02 \pm 0.32$ & $4.39 \pm 0.26$ & $7.29 \pm 0.76$ & $1.89 \pm 0.51$ \\
24 h p.i. & $2.88 \pm 0.24$ & $6.12 \pm 0.35$ & $10.02 \pm 1.22$ & $12.09 \pm 1.17$ & $4.79 \pm 1.06$ & $6.72 \pm 0.79$ \\
\hline
\end{tabular}

Abbreviations: CVB3, Coxsackievirus B3; 4EBP1, elF4E-binding protein 1; p. i., postinfection; S6K, p70S6 kinase

which phosphorylates Akt at Ser-473. Another report has presented that activation of mTORC1, mediated by PI3K/Akt and the inhibitory tuberous sclerosis complex 1/2 (TSC1TSC2), initiates a negative feedback loop that ultimately inhibits PI3K. ${ }^{31}$ Accordingly, we speculate that the continued fully activation of the mTORC1 signal may lead to the feedback inhibition of mTORC2, and thereby the phosphorylation of Akt is blocked and then the activation of mTORC1 is inhibited. Afterwards, the cap-dependent translation is blocked resulting in the blockage of proliferation and differentiation of host cells as well as the decrease of viral protein synthesis. Taken together, it is likely that increased apoptosis in infected cells in the overexpression of Akt is a direct consequence of the increased virus replication at the early stage after infection, while the negative feedback inhibition of Akt phosphorylation becomes the main reason along with the infection time increasing (Figure 8).

In the present study, we also investigated the change of apoptosis and viral replication when 4EBP1 and p70S6K were overexpressed, respectively. We found that overexpression of 4EBP1 promoted the apoptosis rate as well as the VP1 expression after viral infection, and overexpression of p70S6K promoted apoptosis while decreased the VP1 expression at $24 \mathrm{~h} \mathrm{p}$. i. Activated mTOR phosphorylates the downstream effectors 4EBP1 and p70S6K. Being responsible for the capdependent translation of mRNA and the protein synthesis, they are critical components in a pathway regularly co-opted by viruses to ensure translation of their own mRNA. ${ }^{32,33}$ Our previous work has shown that CVB3 infection can activate mTOR/4EBP1 pathway to promote the synthesis and release of the viral protein. ${ }^{16}$ In this study, CVB3 infection directly stimulated PI3K/Akt pathway, keeping the mTOR/4EBP1 pathway activating. Although Akt phosphorylation could be feedback inhibited, there is an alternative mTOR-independent but PI3K-dependent regulation of $4 \mathrm{EBP} 1,{ }^{14}$ maintaining the activation of $\mathrm{mTOR} / 4 \mathrm{EBP} 1$ pathway. Therefore, the VP1 expression increased with the infected time increasing and the apoptosis processed. Being a downstream factor of mTOR, p70S6K is directly and only regulated by mTORC $1 .{ }^{14} \mathrm{An}$ earlier study has reported that at the molecular level, S6K deficiency could protect against the hepatocytes apoptosis, ${ }^{15}$ which is consistent with our results that overexpression of 

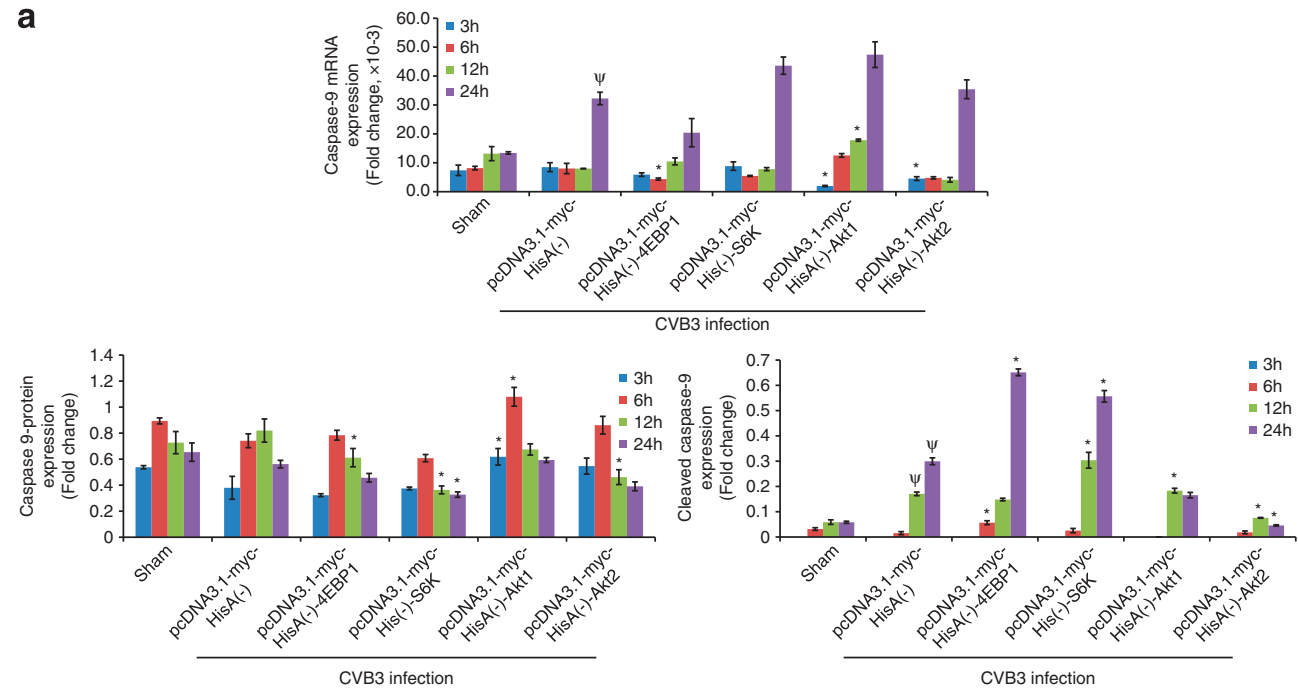

b
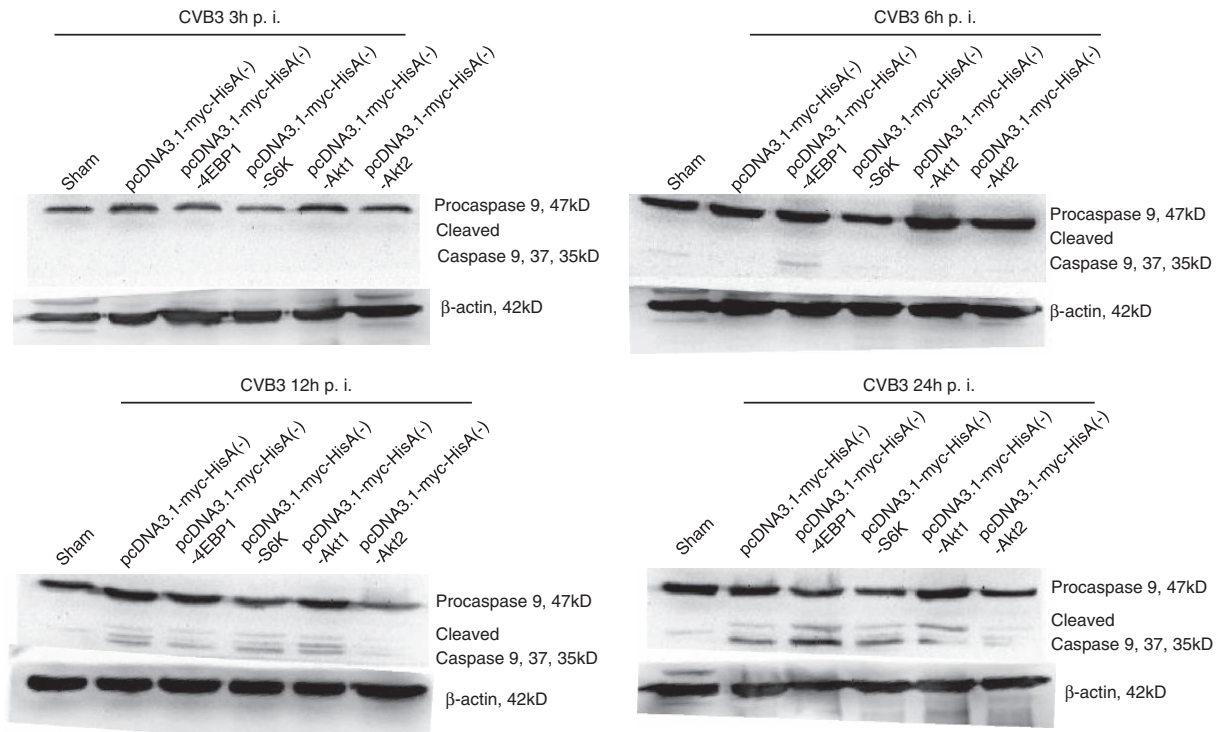

Figure 6 Overexpression of 4EBP1 or p70S6k provokes the CVB3-induced procaspase-9 self-cleavage which is blocked by the overexpression of Akt1 or Akt2. Cell lines containing the above mentioned plasmids were infected with CVB3. Cell lysates were harvested at $3,6,12$ and $24 \mathrm{~h} \mathrm{p}$. i. and caspase-9 activity was determined by semiquantitative PCR and western blot analysis (b). mRNA expressions were determined by real-time fluorescence quantitative PCR (mean \pm S.E.; $n=3$ ) and normalized to internal control $-\beta$-actin, which was arbitrarily set to a value of 1.0 , and these same samples were immunoblotted with an antibody to $\beta$-actin to illustrate equal protein loading (mean \pm S.E.; $n=3$ ) (a). Compared with empty vector groups, mRNA expression in p70S6K group at $6 \mathrm{~h} \mathrm{p}$. i., in Akt 1 group at 3 and $12 \mathrm{~h} \mathrm{p.} \mathrm{i.} \mathrm{and} \mathrm{in} \mathrm{Akt2} \mathrm{group} \mathrm{at} 3 \mathrm{~h}$ p. i. were significant differences ( $\left.{ }^{*} P<0.05\right)$; procaspase-9 expressions in 4 EBP1 group at $12 \mathrm{~h} \mathrm{p}$. i., in p70S6K group at 12 and $24 \mathrm{~h} \mathrm{p}$. i., in Akt1 group at 3 and $6 \mathrm{~h} p$. i. and in Akt2 group at $12 \mathrm{~h} \mathrm{p}$. i. were significant differences $\left({ }^{*} P<0.05\right.$ ); cleaved caspase-9 expressions in $4 \mathrm{EBP} 1 \mathrm{group}$ at 6 and $24 \mathrm{~h} \mathrm{p}$. i., in p70S6K group at 12 and $24 \mathrm{~h} \mathrm{p}$. i., in Akt $1 \mathrm{group}$ at $24 \mathrm{~h} \mathrm{p}$. i. and in Akt2 group at 12 and $24 \mathrm{~h} \mathrm{p}$. i. were significant differences $\left({ }^{\star} P<0.05\right)$. Compared with Sham, cleaved caspase-9 expressions in empty vector group at 12 and $24 \mathrm{~h} \mathrm{p}$. i. were significant differences $\left({ }^{\psi} P<0.05\right)$

Table 4 The Caspase-9 mRNA expression $\left(2^{-\Delta C t}\right.$, mean \pm S.E.; $\left.n=3,1 \times 10^{-3}\right)$

\begin{tabular}{|c|c|c|c|c|c|c|}
\hline & Sham & pc + CVB3 & 4EBP1 + CVB3 & $\mathrm{S} 6 \mathrm{~K}+\mathrm{CVB3}$ & Akt1 + CVB3 & Akt2 + CVB3 \\
\hline $3 \mathrm{~h} \mathrm{p.} \mathrm{i.}$ & $7.40 \pm 1.79$ & $8.49 \pm 1.54$ & $5.91 \pm 0.61$ & $8.86 \pm 1.45$ & $1.97 \pm 0.20$ & $4.55 \pm 0.63$ \\
\hline $6 \mathrm{hp.i.}$ & $8.16 \pm 0.62$ & $8.02 \pm 1.79$ & $4.36 \pm 0.36$ & $5.46 \pm 0.18$ & $12.56 \pm 0.62$ & $4.79 \pm 0.38$ \\
\hline $12 \mathrm{~h} \mathrm{p.} \mathrm{i.}$ & $13.16 \pm 2.43$ & $7.99 \pm 0.09$ & $10.48 \pm 1.20$ & $7.81 \pm 0.52$ & $17.83 \pm 0.37$ & $4.12 \pm 0.80$ \\
\hline 24 h p. i. & $13.42 \pm 0.40$ & $32.25 \pm 2.16$ & $20.41 \pm 4.9$ & $43.60 \pm 2.99$ & $47.41 \pm 4.44$ & $35.43 \pm 3.25$ \\
\hline
\end{tabular}

Abbreviations: CVB3, Coxsackievirus B3; 4EBP1, elF4E-binding protein 1; p. i., postinfection; S6K, p70S6 kinase 
a
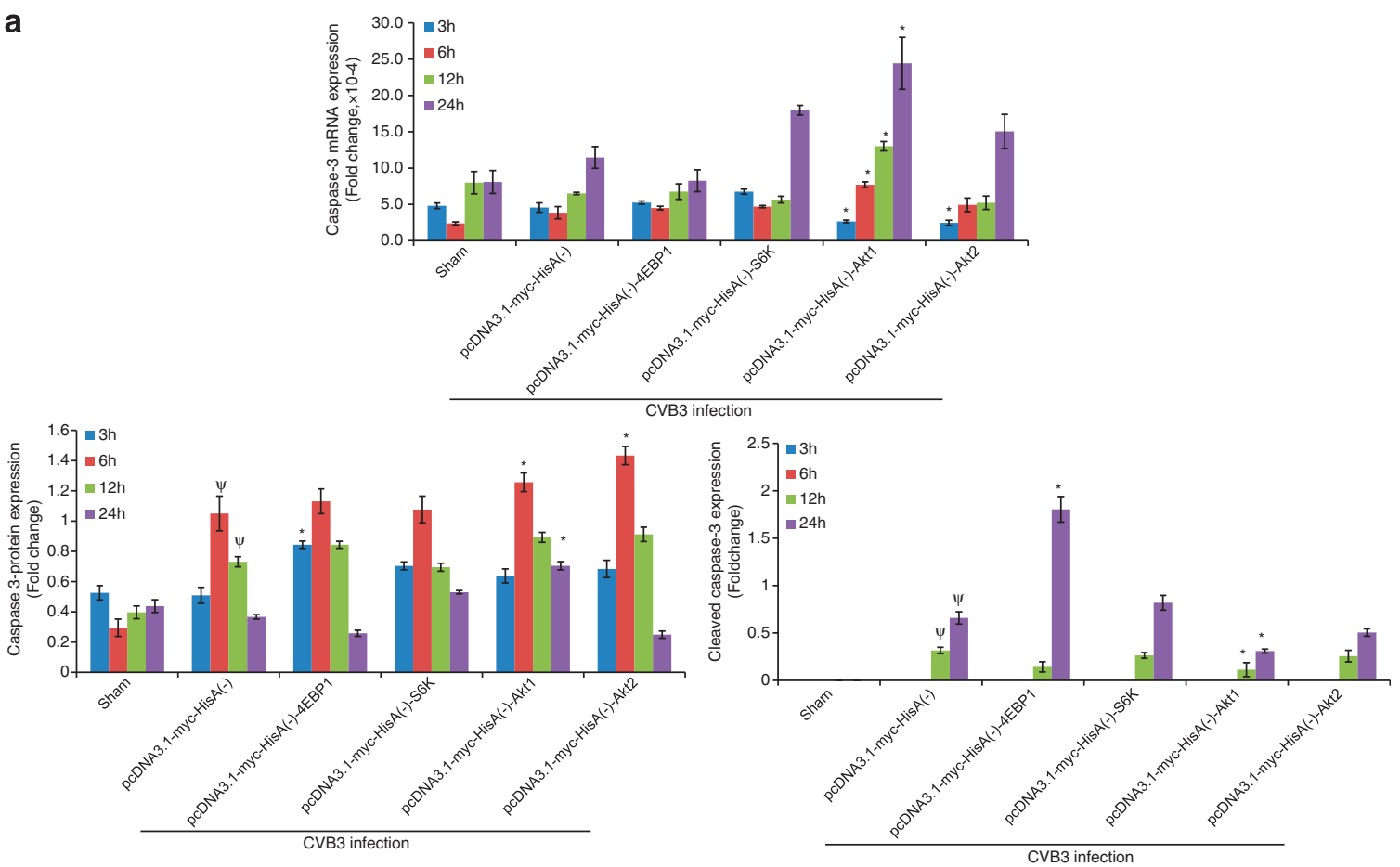

b
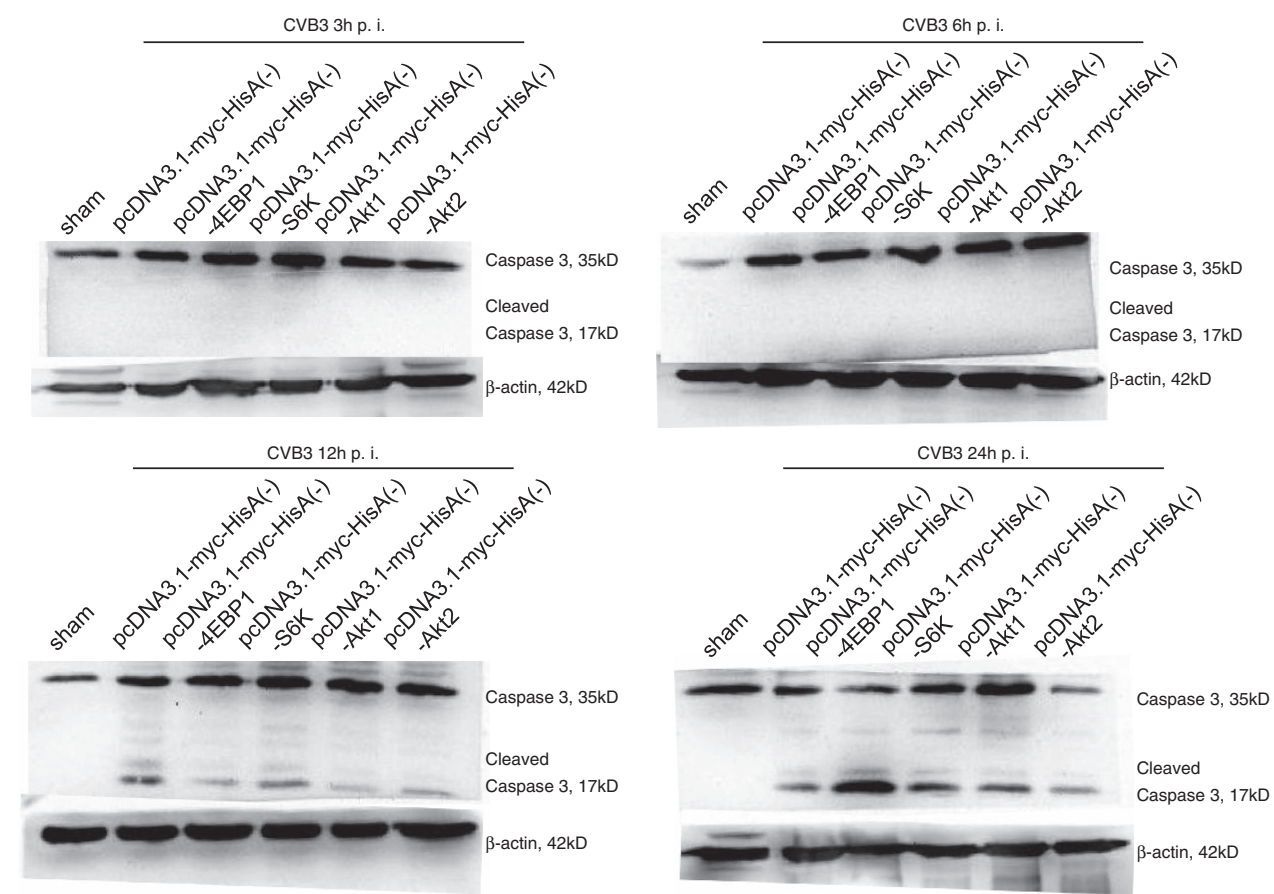

Figure 7 CVB3-induced caspase-3 self-cleavage is stimulated by the overexpression of 4EBP1 but decreased by the overexpression of Akt1. Cell lines containing the above mentioned plasmids were infected with CVB3. Cell lysates were harvested at $3,6,12$ and $24 \mathrm{~h} \mathrm{p}$. i. and caspase-3 activity was determined by semi-quantitative PCR and western blot analysis (b). mRNA expressions were determined by real-time fluorescence quantitative PCR (mean $\pm \mathrm{S}$.E.; $n=3$ ) and normalized to internal control- $\beta$-actin, which was arbitrarily set to a value of 1.0, and these same samples were immunoblotted with an antibody to $\beta$-actin to illustrate equal protein loading (mean \pm S.E.; $n=3$ ) (a). Compared with empty vector groups, mRNA expression in Akt1 group at 3, 6, 12 and $24 \mathrm{~h} \mathrm{p.} \mathrm{i.,} \mathrm{and} \mathrm{in} \mathrm{Akt2} \mathrm{group} \mathrm{at} 3 \mathrm{~h} \mathrm{p}$. i. were significant differences $\left.{ }^{\star} P<0.05\right)$; protein expressions in 4EBP1 group at $3 \mathrm{~h} \mathrm{p}$. i., in Akt1 group at $6,24 \mathrm{~h} \mathrm{p}$. i. and in Akt2 group at $6 \mathrm{~h} \mathrm{p}$. i. were significant differences ( ${ }^{*} P<0.05$ ); cleaved caspase-3 expressions in 4EBP1 group at $24 \mathrm{~h} \mathrm{p}$. i. and in Akt1 group at 12 and $24 \mathrm{~h} \mathrm{p}$. i. were significant differences ( $\left.P<0.05,{ }^{\star \star} P<0.01\right)$. Compared with Sham, in empty vector group, mRNA expression at $6 \mathrm{~h} \mathrm{p}$. i., protein expressions at 6, $12 \mathrm{~h} \mathrm{p}$. i. and cleaved caspase-3 expressions at 12 and $24 \mathrm{~h} \mathrm{p}$. i. were significant differences ( ${ }^{4} P<0.05$ )

p70S6K promotes CVB3-induced apoptosis. Different from $4 \mathrm{EBP} 1$, there is no alternative regulatory way of $\mathrm{p} 70 \mathrm{~S} 6 \mathrm{~K}$, thus when the Akt was negative feedback decreased, which was exacerbated by the further inhibition of PI3K resulted from the overexpression of $\mathrm{p} 70 \mathrm{~S} 6 \mathrm{~K},{ }^{34}$ the $\mathrm{mTOR} / \mathrm{p} 70 \mathrm{~S} 6 \mathrm{~K}$ pathway was inhibited at the late stage of viral infection, and then the 
Table 5 The Caspase-3 mRNA expression ( $2^{-\Delta C t}$, mean \pm S.E.; $\left.n=3,1 \times 10^{-4}\right)$

\begin{tabular}{|c|c|c|c|c|c|c|}
\hline & Sham & pc + CVB3 & 4EBP1 + CVB3 & S6K + CVB3 & Akt1 + CVB3 & Akt2 + CVB3 \\
\hline $3 \mathrm{~h} \mathrm{p.} \mathrm{i.}$ & $4.81 \pm 0.39$ & $4.57 \pm 0.64$ & $5.25 \pm 0.22$ & $6.75 \pm 0.35$ & $2.65 \pm 0.19$ & $2.46 \pm 0.36$ \\
\hline $6 \mathrm{~h}$ p. i. & $2.38 \pm 0.39$ & $3.86 \pm 0.64$ & $4.50 \pm 0.22$ & $4.70 \pm 0.35$ & $7.70 \pm 0.19$ & $4.74 \pm 0.36$ \\
\hline 12 h p. i. & $8.00 \pm 0.21$ & $6.50 \pm 0.84$ & $6.76 \pm 0.25$ & $5.66 \pm 0.15$ & $13.02 \pm 0.39$ & $5.22 \pm 0.93$ \\
\hline 24 h p. i. & $8.08 \pm 1.58$ & $11.47 \pm 1.49$ & $8.25 \pm 1.51$ & $17.97 \pm 0.67$ & $24.43 \pm 3.58$ & $15.05 \pm 2.35$ \\
\hline
\end{tabular}

Abbreviations: CVB3, Coxsackievirus B3; 4EBP1, elF4E-binding protein 1; p. i., postinfection; S6K, p70S6 kinase

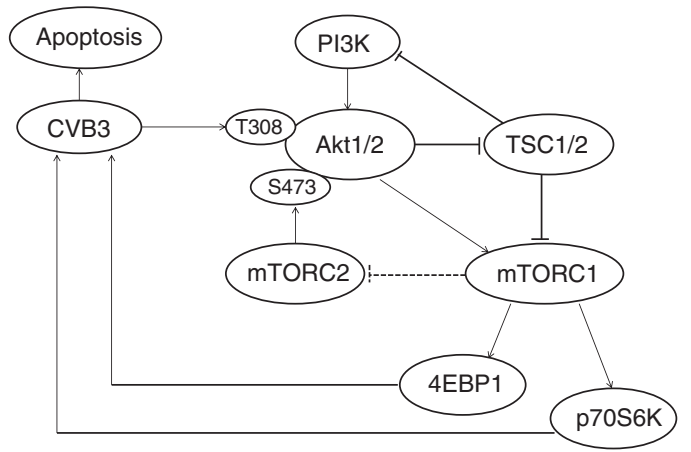

Figure 8 CVB3-induced the PI3K-Akt-mTOR-apoptosis signaling pathway. This example shown is CVB3 stimulating Akt at T308 site, and then phosphorylating mTORC1. Thereby, 4EBP1 and p70S6K are activated and the mRNA translation and protein synthesis are continued, which further promotes the CVB3 replication. Finally, the viral-induced apoptosis is exacerbated. The point in the pathway that continued fully activation of the mTORC1 signal may lead to the feedback inhibition of mTORC2, and thereby the phosphorylation of Akt is blocked and then the activation of mTORC1 is inhibited, which breaks that circle

VP1 synthesis and release were inhibited. These results suggested that overexpression of 4EBP1 promoting the CVB3-induced apoptosis is a direct result of the virus replication, while overexpression of $\mathrm{p} 70 \mathrm{~S} 6 \mathrm{~K}$ probably is the consequence of the regulation of apoptotic factors (Figure 8).

$\mathrm{Bax}$ and Bim are well known to be the members of $\mathrm{BH}$-only proteins, the pro-apoptosis in Bcl-2 family. It has been long reported that Bax can be directly activated by Bim to trigger cytochrome $c$ release and therefore promote the cascade caspase reaction and programmed cell death, which is a major core of the intrinsic apoptosis pathway at the mitochondria. Recently, however, other studies have demonstrated that there is a Bax-/Bak-independent intrinsic apoptosis pathway emerging from a cross talk between the ER and the mitochondria and Bim probably acts as a pro-survival factor in cancer cells making previous conclusion controversial. ${ }^{35,36}$ Caspase, a family of cysteine protease, is the common mediator of apoptosis induced by various stimuli, of which caspase- 3 contributes to the apoptosis execution, while caspase-9 participates in the apoptosis origination. Caspase8 , another member of this family, has recently been reported to have a little relationship with viral-induced apoptosis. ${ }^{37}$ Occurring as an early event that leads to mitochondrially mediated apoptosis through CHOP upregulation and subsequent Bim activation, ER stress has been implicated in various cell types, in which, Bim is essential and indispensable. ${ }^{26,38,39}$ In accordance with that, our results shown that CVB3-induced Bim activation increased at 3 and $6 \mathrm{~h} \mathrm{p}$. i., confirming that Bim is activated at the early period of apoptosis. However, in this study, overexpression of 4EBP1, p70S6K or Akt2 decreased the CVB3-induced Bim activation, while overexpression of Akt1 further stimulated that at 3 and $6 \mathrm{~h} \mathrm{p}$. i. In addition, CVB3induced Bax activation was provoked by the overexpression of Akt1. As we stated before, Bim is critical in the process of mitochondrially mediated apoptosis, and during that process, $\mathrm{Bim}$ is released and then translocating to $\mathrm{Bcl}-2$ resulted in Bax-dependent apoptosis, through which playing its proapoptotic role. In healthy cells, Bax is either located in the cytosol or loosely associated to mitochondria and endoplasmic reticulum, ${ }^{40}$ but when the apoptosis is beginning, Bax is directly activated by Bim activation, through which the downstream factors is stimulated to participate in the apoptosis, ${ }^{41}$ which could be responsible to the highest apoptosis rate of the Akt1 group, consistent with the study that PI3K-dependent Bax/Bak activation promotes the platelets apoptosis. ${ }^{42}$ The classic apoptosis theory considers that activated Bax contributes to form channels on the mitochondrial membrane leading to cytochrome $c$ release, ${ }^{43}$ which can lead to caspase-9 self-cleave and cleaved caspase- 9 further processes other caspase member, initiating a caspase cascade including caspase-3. However, our results shown that overexpression of 4EBP1 or P70S6K decreased the Bim and Bax expression but increased the self-cleavages of caspase-9 and caspase-3; meanwhile, overexpression of Akt1 or Akt2, although stimulated the CVB3-induced Bim and/or Bax activation, they inhibited the self-cleavages of caspase-9 and caspase-3. Recently, some researchers have raised a view that there is a caspase-independent apoptosis pathway. ${ }^{44,45}$ Similar to the report that activated PI3K/Akt pathway inactivates caspase-9 and offers resistance against dexamethasone-induced apoptosis, ${ }^{46}$ overexpression of Akt1 or Akt2 blocked the CVB3-induced caspase- 9 and its self-cleavage at the 12 and $24 \mathrm{~h} \mathrm{p.i.,}$ and then inhibited the self-cleavage of caspase-3. Some earlier reports have shown that in addition to self-cleavage activated by Bim and Bax, procaspase- 9 can also be cleaved in vivo by caspase-3 at Asp 330, which serves as positive feedback to amplify the apoptotic signal in the caspase activation pathway. ${ }^{47,48}$ Another recent study has also demonstrated that a Bax- and Bim-independent apoptosis pathway exists. ${ }^{49}$ Therefore, although overexpression of 4EBP1 or p70S6K did not stimulate the CVB3-induced Bim and Bax activation, it promoted the CVB3-induced apoptosis as well.

In conclusion, based on our data, we suggest that overexpression of 4EBP1, p70S6k, Akt1 or Akt2 promotes the CVB3-induced apoptosis through different mediation 
mechanisms. Overexpression of 4EBP1 or p70S6K promotes the CVB3-induced apoptosis via a Bax and Bim-independent pathway, and overexpression of 4EBP1 could stimulate the viral replication at the meantime. Differently, overexpression of Akt1 or Akt2, promoting the CVB3-induced apoptosis through a caspase-independent pathway, facilitates CVB3 replication at the early stage after infection and inhibits that due to the negative feedback inhibition of Akt phosphorylation.

\section{Materials and Methods}

Plasmid construction. The empty vector (pcDNA3.1-myc-HisA(-)), Homo sapiens Akt2 and its primers were the generous gifts from Dr. Qiaojia Huang (Molecular Medicine Research Center of Fuzhou General Hospital, Nanjing Military Region). The sequences of Homo sapiens 4EBP1, p70S6K and Akt1 were obtained from NCBI and amplified from CDNA of HeLa cells (the primer sequences and semi-quantitative PCR conditions are on the Tables 6 and 7). The pcDNA3.1myc-HisA(-)-4EBP1, pcDNA3.1-myc-HisA(-)-p70S6K, pcDNA3.1-myc-HisA(-)-Akt1 and pcDNA3.1-myc-HisA(-)-Akt2 constructs expressing Homo sapiens 4EBP1, p70S6K, Akt1 and Akt2, respectively, were expressed and extracted from Escherichia coli.

Cell culture and stable transfection. HeLa cells (HeLa S3) were obtained from the Institute of Oncology, Central South University and grown in Dulbecco's modified Eagle's medium (DMEM, Gibco, Life Technologies, Inc. Carlsbad, CA, USA) containing 10\% heat-inactivated fetal bovine serum (FBS, Gibco, Life Technologies, Inc.) at $37^{\circ} \mathrm{C}$ in a humidified incubator with $5 \% \mathrm{CO}_{2}$. HeLa cells at $60 \%$ confluence were transfected with pcDNA3.1-myc-HisA(-)4EBP1, pcDNA3.1-myc-HisA(-)-p70S6K, pcDNA3.1-myc-HisA(-)-Akt1, pcDNA3.1myc-HisA(-)-Akt2 or an empty vector (pcDNA3.1-myc-HisA(-)), respectively. For stable transfection of HeLa cells, $4 \mu \mathrm{g}$ of expression plasmid was introduced by using Lipofectamine 2000 reagent (Invitrogen, Life Technologies) according to the manufacturer's instructions. At 5 to $6 \mathrm{~h}$ posttransfection, the cells were refreshed by the DMEM containing $10 \%$ FBS. And then, after 12-24h, Geneticin (G418) (Gibco, Life Technologies, Inc.) was added as a selective marker at the final concentration of $800 \mu \mathrm{g} / \mathrm{ml}$ for selecting the transfected clones and at the final concentration of $400 \mu \mathrm{g} / \mathrm{ml}$ for the maintenance of transfection during the course of experiments.

Virus propagation and infection. CVB3 Nancy strain was obtained from Shanghai Jiao Tong University School of Medicine, propagated in HeLa cells and

Table 6 Primer sequences

\begin{tabular}{ll}
\hline Genes & Primer sequences \\
\hline $4 E B P 1$ & F: 5'-GGGCTAGCGATGTCCGGGGGCAGCAGCTG-3' \\
& R: 5'-GGAAGCTTAATGTCCATCTCAAACTGTGACTC-3' \\
p70S6K & F: 5'-GGGCTAGCGATGAGGCGACGAAGGAGGCGG-3' \\
& R: 5'-GGGGTACCTAGATTCATACGCAGGTGCTCTG-3' \\
Akt1 & F: 5'-GGGCTAGCGATGAGCGACGTGGCTATTGTG-3' \\
& R: 5'-GGGGTACCGGCCGTGCCGCTGGCCGAGTAG-3'
\end{tabular}

Abbreviations: $F$, forward; $R$, reverse

This table contains the sequences of primers used in the process of plasmid construction. The marked sequences are belonging to the incision enzyme

Table 7 PCR conditions

\begin{tabular}{|c|c|}
\hline Genes & Conditions \\
\hline $4 E B P 1$ & $\begin{array}{l}95^{\circ} \mathrm{C} 2 \min 30 \mathrm{~s} ; 94^{\circ} \mathrm{C} 40 \mathrm{~s}, 64^{\circ} \mathrm{C} 40 \mathrm{~s}, 72^{\circ} \mathrm{C} 40 \mathrm{~s}, 35 \\
\text { cycles; } 72^{\circ} \mathrm{C} 7 \mathrm{~min}\end{array}$ \\
\hline p70S6K & $\begin{array}{l}95^{\circ} \mathrm{C} 2 \min 30 \mathrm{~s} ; 94^{\circ} \mathrm{C} 40 \mathrm{~s}, 66^{\circ} \mathrm{C} 40 \mathrm{~s}, 72^{\circ} \mathrm{C} 1 \mathrm{~min}, 35 \\
\text { cycles; } 72^{\circ} \mathrm{C} 10 \mathrm{~min}\end{array}$ \\
\hline Akt1 & $\begin{array}{l}95^{\circ} \mathrm{C} 2 \min 30 \mathrm{~s} ; 94^{\circ} \mathrm{C} 40 \mathrm{~s}, 64^{\circ} \mathrm{C} 40 \mathrm{~s}, 72^{\circ} \mathrm{C} 1 \mathrm{~min}, 35 \\
\text { cycles; } 72^{\circ} \mathrm{C} 10 \mathrm{~min}\end{array}$ \\
\hline
\end{tabular}

This table contains the PCR conditions in the process of semi-quantitative PCR stored at $-80^{\circ} \mathrm{C}$ in our laboratory. The titer of virus was routinely determined before each experiment. Cell lines containing the above mentioned plasmids were infected at multiplicity of infection of 10 with CVB3 or with DMEM containing $2 \%$ FBS for Sham. After $1 \mathrm{~h}$ infection, cells were washed with phosphate-buffered saline (PBS) and replenished with fresh DMEM containing $2 \% \mathrm{FBS}$, kept growing in a humidified incubator with $5 \% \mathrm{CO}_{2}$.

Cell apoptosis analysis. Apoptosis was determined by fluorescenceactivated cell sorting (FACS) analysis of cells stained with Annexin-V-FITC and propidium iodide (PI, Promega, Beijing, China) by a flow cytometer. At each time point, cells were harvested using $0.25 \%$ EDTA-Trypsin (Gibco, Life Technologies, Inc.). After centrifugation, cell pellets were washed twice with cold PBS, and then the cells pellets were incubated with Annexin-V-FITC and PI to achieved double staining, according to the manufacturer's instructions. The mixture was incubated in the dark for $15 \mathrm{~min}$ at room temperature. Afterwards, $400 \mu \mathrm{l}$ of $1 \times$ binding buffer was added to each tube and cells were immediately analyzed by FACS Calibur flow cytometry (Becton, Dickinson and Company, Franklin Lakes, NJ, USA).

Real-time fluorescence quantitative PCR. HeLa cells either untransfected or transfected with different plasmids were harvested at each time point, and firstly had mRNA extracted following the method of RNA Extracted Kit (Omega Bio-Tek, Inc., Norcross, GA, USA). Next, mRNA was reverse transcribed into cDNA following the RevertAidTM First Strand cDNA Synthesis Kit (Thermo Fisher Scientific Inc., Waltham, MA, USA). At last, real-time fluorescence quantitative PCR amplification was done following the SYBGREEN PCR Master Mix Kit (ABI, Life Technologies, Inc.). The primer sequences are on the table below (Table 8). The amplification profile was $10 \mathrm{~min}$ at $95^{\circ} \mathrm{C}, 15 \mathrm{~s}$ at $95^{\circ} \mathrm{C}, 30 \mathrm{~s}$ at $60^{\circ} \mathrm{C}$ for 40 cycles. Signal of a gene was normalized with $\beta$-actin using the formula $\Delta C_{T}=C_{T}$ target $-C_{T}$ reference. At last, $2^{-\Delta \mathrm{Ct}}$ method was used to calculate the differences of mRNA transcript level.

Western blot analysis. HeLa cells either untransfected or transfected with different genes were washed twice with ice-cold PBS and then kept on ice for $10 \mathrm{~min}$. Then $80 \mu$ l lysis buffer (Beyotime Institute of Biotechnology, Beijing, China) containing $0.1 \%$ phenylmethylsulfony (Cwbio, Beijing, China) was added in each well. Afterwards, cell lysates were collected by scraping and centrifuged at 12000 r.p.m. for $15 \mathrm{~min}$ at $4{ }^{\circ} \mathrm{C}$, and then the precipitate was discarded. Protein concentration was determined by the Enhanced BCA protein Assay Kit (Beyotime Institute of Biotechnology). Extracted protein $(30 \mu \mathrm{g})$ were fractionated on sodium dodecyl sulfate-10-12\% polyacrylamide gels, electrophoretically transferred to $0.45 \mu \mathrm{m}$ PVDF membranes (Millipore Corporation, Billerica, MA, USA), and blocked with PBS containing $0.5 \%$ Triton-100 (Cwbio) and $5 \%$ nonfat dry milk for $1 \mathrm{~h}$. Afterwards, the membrane was incubated with the primary antibody (polyclonal antibody to Myc tag (Gene Tex, Inc., Irvine, CA, USA), monoclonal anti-Akt1 antibody (Cell Signaling Technology, Danvers, MA, USA), monoclonal anti-Akt2 antibody (Cell Signaling Technology), monoclonal anti-4EBP1 antibody (Cell Signaling Technology), monoclonal anti-p70S6K antibody (Cell Signaling Technology), monoclonal anti-enterovirus antibody (Dako Co., Copenhagen, Denmark), monoclonal anti-bim antibody (Cell Signaling Technology), polyclonal anti-bax antibodies (Cell Signaling Technology), monoclonal anti-caspase-9

Table 8 Primer sequences

\begin{tabular}{|c|c|}
\hline Genes & Primer sequences \\
\hline CVB3 & $\begin{array}{l}\text { F: 5'-GTGGTGGGCTATGGAGTATG-3' } \\
\text { R: 5'-ATTGCACAGAGTCAAGGGT-3'3 }\end{array}$ \\
\hline Bim & $\begin{array}{l}\text { F: } 5^{\prime} \text {-AACGAGAATCAAGATCACTGA-3' } \\
\text { R: } 5^{\prime} \text {-CTTGGACATCACAAATAGGACA-3' }\end{array}$ \\
\hline Bax & $\begin{array}{l}\text { F: 5'-GGGATGGCCTCCTTTCCTAC-3' } \\
\text { R: 5'-TTCCAGATGGTGAGTGAGGCA-3' }\end{array}$ \\
\hline Caspase & $\begin{array}{l}9 \mathrm{~F}: 5^{\prime} \text {-CCAGTGGACATTGGTTCTGG-3' } \\
\text { R: } 5^{\prime} \text { TCACGGCAGAAGTTCACATT } 3^{\prime}\end{array}$ \\
\hline Caspase & $\begin{array}{l}3 \text { F: } 5^{\prime}-C A G A G G G G A T C G T T G T A G A A G-3^{\prime} \\
\text { R: } 5^{\prime}-C A T A C A A G A A G T C G G C C T C C A-3^{\prime}\end{array}$ \\
\hline$\beta$-actin & $\begin{array}{l}\text { F: } 5^{\prime}-\text { CATCCTGCGTCTGGACCTGG-3' } \\
\text { R: } 5^{\prime} \text {-TAATGTCACGCACGATTTCC-3' }\end{array}$ \\
\hline
\end{tabular}

Abbreviations: $F$, forward; $R$, reverse

This table contains the sequences of primers used in the process of real-time fluorescence quantitative PCR (RTFQ PCR) 
antibody (Cell Signaling Technology), polyclonal anti-caspase-3 antibodies (Cell Signaling Technology) and monoclonal anti- $\beta$-actin antibody (Proteintech Group, Inc., Chicago, IL, USA) at $4{ }^{\circ} \mathrm{C}$ overnight, followed by incubation with horseradish peroxidase-conjugated secondary antibodies (Beyotime Institute of Biotechnology, Beijing, China). At last, protein expression was detected by enhanced chemiluminescence (Pierce Professional Resources, Holmdel, NJ, USA).

Immunofluorescence. HeLa cells either untransfected or transfected with plasmids mentioned above were grown on cover glasses and infected with CVB3, then washed thrice with cold PBS at each time point, fixed in cold paraformldehyde for $30 \mathrm{~min}$, and blocked with PBS containing 5\% Tween (Cwbio) and $3 \%$ bovine serum albumin for $2 \mathrm{~h}$ at $4{ }^{\circ} \mathrm{C}$. The cells were then incubated with monoclonal anti-enterovirus antibody (Dako Co.) for $4 \mathrm{~h}$ at room temperature, followed by fluorophore-labeled donkey anti-mouse $\lg \mathrm{G}(\mathrm{H}+\mathrm{L})$ antibody (Invitrogen, Life Technologies). At last, DAPI (Roche Group, Basel, Switzerland) was incubated for $3 \mathrm{~min}$ at room temperature to dye the nucleus. After washed thrice with PBS, the cover glasses were mounted onto glass microscope slides and observed under Olympus microscope (Olympus Corporation, Tokyo, Japan) equipped with a Metamorph image acquisition system (DP2-BSW software, Olympus Corporation).

Transmission electron microscope. HeLa cells either untransfected or transfected with plasmids mentioned above were infected with CVB3 and collected $24 \mathrm{~h} \mathrm{p}$. i. Centrifuged at 2500 r.p.m. for $10 \mathrm{~min}$ at room temperature, the tubes were slowly added with cold $2.5 \%$ glutaraldehyde. Fixed for $24 \mathrm{~h}$, the cells were fixed again with $2 \%$ osmium tetroxide for $2 \mathrm{~h}$, after that, the cells were dehydrated with $50,70,90$ and $100 \%$ acetone successively. Then, the cells were soaked for $24 \mathrm{~h}$ with epoxy resin mixed with an equal volume of pure acetone and embedded with Epoxiaquivalentgewicht 145-160 (Epon812), dodecenylsuccinic anhydride, methyl nadic anhydride and dimethylaminomethyt phenol (DMP30). Next, cell slice of about $500 \AA$ was completed by the special slicer (LKB-, Sweden). At last, the dyed slices were observed and taken pictures via TEM (Hitachi 7500, Tokyo, Japan).

Statistical analysis. Two-way analysis of variance with multiple comparisons and paired Student's $t$-tests were performed. Data were presented as the mean \pm S.E. The $P$-value of $<0.05$ was considered significant.

\section{Conflict of Interest}

The authors declare no conflict of interest.

Acknowledgements. We appreciate that Dr. Qiaojia Huang (Molecular Medicine Research Center of Fuzhou General Hospital, Nanjing Military Region) provided us the necessary empty vector, Homo sapiens Akt2 and its primers, and the Center Laboratory at the Third Xiangya Hospital of the Central South University provided us with the experimental equipment and technical guidance necessary to complete our work. This subject was funded by the Fundamental Research Funds for the Central Universities of Central South University and National Natural Science Foundation (Grant no. 30973233).

1. Kinross KM, Brown DV, Kleinschmidt M, Jackson S, Christensen J, Cullinane $C$ et al. In vivo activity of combined PI3K/mTOR and MEK inhibition in a Kras(G12D); Pten deletion mouse model of ovarian cancer. Mol Cancer Ther 2011; 10: 1440-1449.

2. Bellacosa A, Kumar CC, Di Cristofano A, Testa JR. Activation of AKT kinases in cancer: implications for therapeutic targeting. Adv Cancer Res 2005; 94: 29-86.

3. Plas DR, Thompson CB. Akt-dependent transformation: there is more to growth than just surviving. Oncogene 2005; 24: 7435-7442.

4. Baker SJ. PTEN enters the nuclear age. Cell 2007; 128: 25-28.

5. Virtakoivu R, Pellinen T, Rantala JK, Perälä M, Ivaska J. Distinct roles of AKT isoforms in regulating beta1-integrin activity, migration, and invasion in prostate cancer. $\mathrm{Mol}$ Biol Cell 2012; 23: 3357-3369.

6. Testa JR, Bellacosa A. AKT plays a central role in tumorigenesis. Proc Natl Acad Sci USA 2001; 98: 10983-10985.

7. Agarwal E, Brattain MG, Chowdhury S. Cell survival and metastasis regulation by Akt signaling in colorectal cancer. Cell Signal 2013; 25: 1711-1719; (E-pub ahead of print).

8. Koseoglu S, Lu Z, Kumar C, Kirschmeier P, AKT1 Zou J. AKT2 and AKT3-dependent cell survival is cell line-specific and knockdown of all three isoforms selectively induces apoptosis in 20 human tumor cell lines. Cancer Biol Ther 2007; 6: 755-762.
9. Xu F, Kang $\mathrm{Y}$, Zhang $\mathrm{H}$. Akt1 comprised antibacterial response through regulating macrophage polarization. J Infect Dis 2013; 208: 528-538.

10. Jensen PJ, Gunter LB, Carayannopoulos MO. Akt2 modulates glucose availability and downstream apoptotic pathways during development. J Biol Chem 2010; 285: 17673-17680.

11. Ding L, Biswas S, Morton RE, Smith JD, Hay N, Byzova TV et al. Akt3 deficiency in macrophages promotes foam cell formation and atherosclerosis in mice. Cell Metab 2012; 15: $861-872$

12. Hoang B, Benavides A, Shi Y, Yang Y, Frost P, Gera J et al. The PP242 mammalian target of rapamycin (mTOR) inhibitor activates extracellular signal-regulated kinase (ERK) in multiple myeloma cells via a target of rapamycin complex 1 (TORC1)/eukaryotic translation initiation factor $4 \mathrm{E}$ (elF-4E)/RAF pathway and activation is a mechanism of resistance. J Biol Chem 2012; 287: 21796-21805.

13. Xu Q, Liu LZ, Qian X, Chen Q, Jiang Y, Li D et al. MiR-145 directly targets $p 70 S 6 K 1$ in cancer cells to inhibit tumor growth and angiogenesis. Nucleic Acids Res 2012; 40: 761-774.

14. Nawroth R, Stellwagen F, Schulz WA, Stoehr R, Hartmann A, Krause BJ et al. S6K1 and 4E-BP1 are independent regulated and control cellular growth in bladder cancer. PLoS One 2011; 6: e27509.

15. González-Rodriguez A, Alba J, Zimmerman V, Kozma SC, Valverde AM. S6K1 deficiency protects against apoptosis in hepatocytes. Hepatology 2009; 50: 216-229.

16. Chen CY, Sun YN, Yang ZC. Effeet of rapamycin on mTOR and elF-4E expression in coxsackievirus B3-induced rat myocardial cells. Zhong Nan Da Xue Xue Bao Yi Xue Ban 2008; 33: 612-617.

17. Shaw RJ, Ras Cantley LC. $\mathrm{PI}(3) \mathrm{K}$ and $\mathrm{mTOR}$ signalling controls tumour cell growth. Nature 2006; 441: 424-430.

18. Esfandiarei M, Luo H, Yanagawa B, Suarez A, Dabiri D, Zhang J et al. Protein kinase B/Akt regulates coxsackievirus $B 3$ replication through a mechanism which is not caspase dependent. J Virol 2004; 78: 4289-4298.

19. Li X, Zhang J, Chen Z, Yang L, Xing X, Ma X et al. Both PI3K- and mTOR-signaling pathways take part in CVB3-induced apoptosis of hela cells. DNA Cell Biol 2013; 32: 359-370.

20. Liu Z, Zhang HM, Yuan J, Ye X, Taylor GA, Yang D. The immunity-related GTPase Irgm3 relieves endoplasmic reticulum stress response during coxsackievirus B3 infection via a PI3K/Akt dependent pathway. Cell Microbiol 2012; 14: 133-146.

21. Esfandiarei M, Suarez A, Amaral A, Si X, Rahmani M, Dedhar S et al. Novel role for integrin-linked kinase in modulation of coxsackievirus B3 replication and virus-induced cardiomyocyte injury. Circ Res 2006; 99: 354-361.

22. Puthalakath H, O'Reilly LA, Gunn P, Lee L, Kelly PN, Huntington ND et al. ER stress triggers apoptosis by activating BH3-only protein Bim. Cell 2007; 129: 1337-1349.

23. Brem GJ, Mylonas I, Bruning A. Eeyarestatin causes cervical cancer cell sensitization to bortezomib treatment by augmenting ER stress and CHOP expression. Gynecol Oncol 2013; 128: 383-390.

24. Coffey CM, Sheh A, Kim IS, Chandran K, Nibert ML, Parker JS. Reovirus outer capsid protein micro1 induces apoptosis and associates with lipid droplets, endoplasmic reticulum, and mitochondria. J Virol 2006; 80: 8422-8438.

25. Smith JA, Schmechel SC, Raghavan A, Abelson M, Reilly C, Katze MG et al. Reovirus induces and benefits from an integrated cellular stress response. J Virol 2006; 80: 2019-2033.

26. Soo KY, Atkin JD, Farg M, Walker AK, Horne MK, Nagley P et al. Bim links ER stress and apoptosis in cells expressing mutant SOD1 associated with amyotrophic lateral sclerosis. PLoS One 2012; 7: e35413.

27. Wisniewski ML, Werner BG, Hom LG, Anguish LJ, Coffey CM, Parker JS. Reovirus infection or ectopic expression of outer capsid protein micro1 induces apoptosis independently of the cellular proapoptotic proteins Bax and Bak. J Virol 2011; 85: 296-304.

28. Hwang JH, Hsu CJ, Yu WH, Liu TC, Yang WS. Diet-induced obesity exacerbates auditory degeneration via hypoxia, inflammation, and apoptosis signaling pathways in $\mathrm{CD} / 1$ mice. PLoS One 2013; 8: e60730.

29. Esfandiarei M, Boroomand S, Suarez A, Si X, Rahmani M, McManus B. Coxsackievirus B3 activates nuclear factor kappa B transcription factor via a phosphatidylinositol-3 kinase/ protein kinase B-dependent pathway to improve host cell viability. Cell Microbiol 2007; 9: 2358-2371.

30. Yih LH, Hsu NC, Wu YC, Yen WY, Kuo HH. Inhibition of AKT enhances mitotic cell apoptosis induced by arsenic trioxide. Toxicol Appl Pharmacol 2013; 267: 228-237.

31. Dalle PP, Sonntag AG, Thien A, Prentzell MT, Gödel M, Fischer S et al. A dynamic network model of mTOR signaling reveals TSC-independent mTORC2 regulation. Sci Signal 2012; 5: a25.

32. Kudchodkar SB, Yu YJ, Maguire TG, Alwine JC. Human cytomegalovirus infection induces rapamycin-insensitive phosphorylation of downstream effectors of mTOR kinase. J Virol 2004; 78: 11030-11039.

33. Schneider RJ, Mohr I. Translation initiation and viral tricks. Trend Biochem Sci 2003; 28 : 130-136.

34. Zhang J, Gao Z, Yin J, Quon MJ, Ye J. S6K directly phosphorylates IRS-1 on Ser-270 to promote insulin resistance in response to TNF-(alpha) signaling through IKK2. J Biol Chem 2008; 283: 35375-35382

35. Zamorano S, Rojas-Rivera D, Lisbona F, Parra V, Court FA, Villegas R et al. A BAX/BAK and cyclophilin D-independent intrinsic apoptosis pathway. PLoS One 2012; 7: e37782. 
36. Gogada R, Yadav N, Liu J, Tang S, Zhang D, Schneider A et al. Bim, a proapoptotic protein, upregulated via transcription factor E2F1-dependent mechanism, functions as a prosurvival molecule in cancer. J Biol Chem 2013; 288: 368-381.

37. Imao T, Nagata S. Apaf-1- and Caspase-8-independent apoptosis. Cell Death Differ 2013; 20: 343-352

38. Ghosh AP, Klocke BJ, Ballestas ME, Roth KA. CHOP potentially co-operates with FOXO3a in neuronal cells to regulate PUMA and BIM expression in response to ER stress. PLoS One 2012; 7: e39586.

39. Shinde VM, Sizova OS, Lin JH, LaVail MM, Gorbatyuk MS. ER stress in retinal degeneration in S334ter Rho rats. PLoS One 2012; 7: e33266.

40. Kudo W, Lee HP, Smith MA, Zhu X, Matsuyama S, Lee HG. Inhibition of Bax protects neuronal cells from oligomeric Abeta neurotoxicity. Cell Death Dis 2012; 3: e309.

41. Cartron PF, Loussouarn D, Campone M, Martin SA, Vallette FM. Prognostic impact of the expression/phosphorylation of the BH3-only proteins of the $\mathrm{BCL}-2$ family in glioblastoma multiforme. Cell Death Dis 2012; 3: e421.

42. Zhang S, Ye J, Zhang Y, Xu X, Liu J, Zhang SH et al. P2Y12 protects platelets from apoptosis via PI3k-dependent Bak/Bax inactivation. J Thromb Haemost 2013; 11: 149-160.

43. Willis SN, Fletcher Jl, Kaufmann T, Van Delft MF, Chen L, Czabotar PE et al. Apoptosis initiated when $\mathrm{BH} 3$ ligands engage multiple Bcl-2 homologs, not Bax or Bak. Science 2007 315: 856-859.

44. Jacquin MA, Chiche J, Zunino B, Bénéteau $M$, Meynet $O$, Pradelli LA et al. GAPDH binds to active Akt, leading to Bcl-xL increase and escape from caspase-independent cell death. Cell Death Differ 2013; 20: 1043-1054.
45. Kim JO, Kim JY, Rhee DK, Pyo S. Streptococcus pneumoniae ClpP protease induces apoptosis via caspase-independent pathway in human neuroblastoma cells: cytoplasmic relocalization of p53. Toxicon 2013; 70: 142-152.

46. Zong H, Bastie CC, Xu J, Fassler R, Campbell KP, Kurland IJ et al. Insulin resistance in striated muscle-specific integrin receptor beta1-deficient mice. J Biol Chem 2009; 284: 4679-4688.

47. Zou H, Yang R, Hao J, Wang J, Sun C, Fesik SW et al. Regulation of the Apaf-1/caspase-9 apoptosome by caspase-3 and XIAP. J Biol Chem 2003; 278: 8091-8098.

48. Denault JB, Eckelman BP, Shin H, Pop C, Salvesen GS. Caspase 3 attenuates XIAP (X-linked inhibitor of apoptosis protein)-mediated inhibition of caspase 9. Biochem J 2007; 405: 11-19.

49. Miller AV, Hicks MA, Nakajima W, Richardson AC, Windle JJ, Harada $H$ Paclitaxel-Induced Apoptosis Is BAK-Dependent, but BAX and BIM-Independent in Breast Tumor. PLoS One 2013; 8: e60685.

Cell Death and Disease is an open-access journal published by Nature Publishing Group. This work is licensed under a Creative Commons Attribution-NonCommercialNoDerivs 3.0 Unported License. To view a copy of this license, visit http://creativecommons.org/licenses/by-nc-nd/3.0/ 